2011

\title{
Anaerobic Oxidation of Methane and the Stoichiometry of Remineralization Processes in Continental Margin Sediments
}

\author{
David J. Burdige \\ Old Dominion University, dburdige@odu.edu
}

Tomoko Kamada

Follow this and additional works at: https://digitalcommons.odu.edu/oeas_fac_pubs

Part of the Fresh Water Studies Commons, $\underline{\text { Marine Biology Commons, and the Oceanography }}$ Commons

\section{Repository Citation}

Burdige, David J. and Kamada, Tomoko, "Anaerobic Oxidation of Methane and the Stoichiometry of Remineralization Processes in Continental Margin Sediments" (2011). OEAS Faculty Publications. 65.

https://digitalcommons.odu.edu/oeas_fac_pubs/65

\section{Original Publication Citation}

Burdige, D.J., \& Komada, T. (2011). Anaerobic oxidation of methane and the stoichiometry of remineralization processes in continental margin sediments. Limnology and Oceanography, 56(5), 1781-1796. doi: 10.4319/lo.2011.56.5.1781 


\title{
Anaerobic oxidation of methane and the stoichiometry of remineralization processes in continental margin sediments
}

\author{
David J. Burdigea,* and Tomoko Komadab \\ a Department of Ocean, Earth, and Atmospheric Sciences, Old Dominion University, Norfolk, Virginia \\ b Romberg Tiburon Center, San Francisco State University, Tiburon, California
}

\begin{abstract}
In many coastal and continental margin sediments, pore-water property-property plots yield values of $r_{\mathrm{C}: \mathrm{S}}$, the stoichiometric ratio of dissolved inorganic carbon (DIC) produced to sulfate reduced, that are lower than the commonly assumed value of 2 . Remineralization of organic matter more reduced than $\mathrm{CH}_{2} \mathrm{O}$ can cause such observations, as can DIC loss due to authigenic carbonate precipitation. However, through studies of Santa Monica Basin sediments, we have observed that these observations could also be related to the occurrence of anaerobic oxidation of methane (AOM) in sediments. Specifically, using a reactive transport sediment model, we have shown that AOM driven by an "external" methane source (e.g., an upward flux from ancient gas hydrates) can lead to values of $r_{\mathrm{C}: \mathrm{S}}<2$. This contrasts with what is observed when AOM is driven by methane produced during in situ methanogenesis, resulting from the deposition of reactive organic matter to the sediment surface. This situation does not lead to deviations in the value of $r_{\mathrm{C}: \mathrm{S}}$ from that seen solely for the occurrence of organic matter remineralization by sulfate reduction. With real pore-water data, if carbonate precipitation is adequately accounted for, observed deviations in values of $r_{\mathrm{C}: \mathrm{S}}$ from predicted end-member values for organic matter remineralization and $\mathrm{AOM}$ can provide information about the occurrence of AOM and upward methane fluxes in sediments.
\end{abstract}

In many anoxic sediments, dissolved inorganic carbon (DIC) production is coupled to bacterial sulfate reduction, and diffusion is the predominant pore-water solute transport process. Neglecting for now any possible carbonate precipitation or dissolution (which is discussed below in further detail), a property-property plot of the sediment pore-water DIC concentration vs. sulfate concentration (or a plot of their concentration changes with respect to bottom water values) will have a slope given by,

$$
\frac{d C}{d S}=-r_{\mathrm{C}: \mathrm{S}} \frac{D_{\mathrm{s}}}{D_{\mathrm{c}}}
$$

where $C$ is DIC, $S$ is sulfate, $D_{i}$ is the bulk sediment diffusion coefficient for solute $i$ (where $i=C$ or $S$ ) and $r_{\mathrm{C}: \mathrm{S}}$ is the stoichiometric ratio of DIC produced to sulfate reduced. Thus from the slope of this pore-water DIC : sulfate property-property plot, we can estimate $r_{\mathrm{C}: \mathrm{s}}$.

In a more general sense, the use of such pore-water property-property plots to examine the stoichiometry of biogeochemical processes occurring in sediments was originally described by Berner (1977). He showed that if the transport processes affecting two solutes are well described, and if the production or consumption reactions affecting the solutes are tightly coupled, then these property-property plots can be used to determine the stoichiometric ratio of solute production or consumption (also see similar derivations in Hammond et al. 1999).

Returning to the specific example cited above, if we assume that the organic matter being remineralized is $\mathrm{CH}_{2} \mathrm{O}$ (i.e., has an average oxidation state, $o x$, equal to 0 ),

\footnotetext{
*Corresponding author: dburdige@odu.edu
}

then we can write the following equation,

$$
2 \mathrm{CH}_{2} \mathrm{O}+\mathrm{SO}_{4}^{2-} \rightarrow 2 \mathrm{HCO}_{3}^{-}+\mathrm{H}_{2} \mathrm{~S}
$$

and we see that the ratio of moles of DIC produced to sulfate reduced (i.e., $r_{\mathrm{C}: \mathrm{S}}$ ) equals 2 . However, in many coastal and continental margin sediments, property-property plots yield values of $r_{\mathrm{C}: \mathrm{S}}<2$ (Jahnke 1990; Berelson et al. 2005; Jørgensen and Parkes 2010). Several explanations have been put forth to explain these observations, including the remineralization (oxidation) of organic matter that is on average more reduced than $\mathrm{CH}_{2} \mathrm{O}$, as well as the precipitation of calcium carbonate in the sediments. However, as a part of our studies of sediments in the Santa Monica Basin, California Borderland region, we have observed that there may be a third explanation for these observations related to the occurrence of anaerobic oxidation of methane $(\mathrm{AOM})$ in the sediments and, more importantly, the source of the methane that drives this AOM.

The goal then of this paper is to examine the factors that cause such deviations in $r_{\mathrm{C}: \mathrm{S}}$ values based on estimates determined from pore-water property-property plots. The approach we will use involves examining the results of our recent studies in Santa Monica Basin sediments, and results obtained with a coupled nonlinear reaction-transport model for anoxic marine sediments. With these results, we will specifically examine how the occurrence of AOM in sediments, and the possible sources of the methane that drive this AOM, affects both sediment DIC production and sulfate reduction, as well as parameters such as $r_{\mathrm{C}: \mathrm{S}}$ that can be derived from pore-water property-property plots.

Deviations in $\mathrm{r}_{C: S}$ due to differences in sedimentary organic matter composition - In anoxic sediments where 
sulfate reduction dominates organic matter remineralization, Burdige (2006) has shown that $r_{\mathrm{C}: \mathrm{S}}$ is related to the average carbon oxidation state of the organic matter undergoing remineralization $(=o x)$ according to

$$
r_{\mathrm{C}: \mathrm{S}}=8 /(4-o x)
$$

allowing one to estimate $o x$ through the value of $r_{\mathrm{C}: \mathrm{S}}$ determined from a DIC:sulfate pore-water propertyproperty plot as described above.

In a compilation of estimates of $o x$ based on a wide range of experimental and modeling techniques (Burdige 2006), bulk naturally occurring marine organic matter was found, on average, to be more reduced than $\mathrm{CH}_{2} \mathrm{O}$ (ox $=$ 0 ), with $o x$ equal to approximately -0.5 to -0.7 . When $o x$ is $<0$, more sulfate is reduced per mole of DIC produced from the oxidation of this more reduced organic matter, and $r_{\mathrm{C}: \mathrm{S}}$ is therefore $<2$ (Eq. 3). For example, if sediment organic matter has an average $o x$ value of -0.7 then $r_{\mathrm{C}: \mathrm{S}}$ decreases from 2 to 1.7 , whereas if $o x=-0.5$, then $r_{\mathrm{C}: \mathrm{S}}=$ 1.8. More specifically, oxidation of hydrocarbons, which are also more reduced than $\mathrm{CH}_{2} \mathrm{O}$, will similarly result in $r_{\mathrm{C}: \mathrm{S}}<2$. In the extreme, if $o x=-4$, the material undergoing oxidation is methane, and based on the stoichiometry of anaerobic oxidation of methane (AOM),

$$
\mathrm{CH}_{4}+\mathrm{SO}_{4}^{2-} \rightarrow \mathrm{HCO}_{3}^{-}+\mathrm{HS}^{-}+\mathrm{H}_{2} \mathrm{O}
$$

we see that $r_{\mathrm{C}: \mathrm{S}}=1$, consistent with Eq. 3 .

At the same time, studies of some sediments yield values of $r_{\mathrm{C}: \mathrm{S}}$ that are significantly smaller than even 1.7. In studies of Santa Monica Basin sediments, Jahnke (1990) observed an $r_{\mathrm{C}: \mathrm{S}}$ value of 1.21 on the basis of a propertyproperty plot of titration alkalinity vs. sulfate for pore waters in the upper $\sim 50 \mathrm{~cm}$ of sediment. In our recent studies of these same sediments, we observed essentially the identical value $(1.17 \pm 0.03)$ on the basis of a DIC: sulfate property-property plot (Fig. 1). Similar observations have also been made in other coastal and continental margin sediments (Berelson et al. 2005; Jørgensen and Parkes 2010 ), where $r_{\mathrm{C}: \mathrm{S}}$ values as low as $\sim 1.3-1.5$ have been observed. Taken at face value, these ratios give $o x$ values ranging from -1.3 to -2.2 on the basis of Eq. 3. An adequate explanation for such observations has not been presented because, for sediments in which the organic matter being remineralized is supplied to the sediments primarily by deposition at the sediment surface, it is difficult to envision a situation in which such extremely reduced organic matter is added to the sediments in any significant amount.

Deviations in $\mathrm{r}_{C: S}$ due to precipitation of authigenic carbonate minerals - Precipitation or dissolution of carbonate minerals will also lead to deviations in estimates of $r_{\mathrm{C}: \mathrm{S}}$ obtained from DIC: sulfate property-property plots, with dissolution increasing the slope of the best-fit line through the data (and hence increasing the apparent value of $r_{\mathrm{C}: \mathrm{S}}$ obtained from the plot) and precipitation decreasing this slope and the resulting apparent $r_{\mathrm{C}: \mathrm{S}}$ value. Our work (described in "Results") and that of Berelson et al. (2005) both indicate that carbonate precipitation occurs at depth

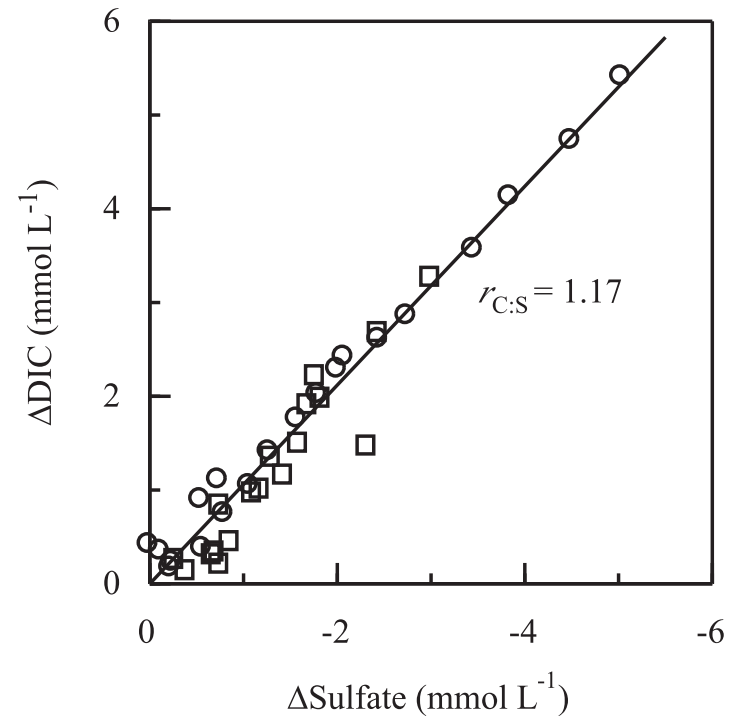

Fig. 1. A DIC : sulfate pore-water property-property plot for cores collected in Santa Monica Basin. Different symbols represent data from different cores. Note that here (and in all other property-property plots) " $\Delta$ " concentrations are relative to bottom water values, and the slope of the best-fit line through the data $(d C / d S)$ is used to calculate $r_{\mathrm{C}: \mathrm{S}}$ with Eq. 1.

(greater than $\sim 45-100 \mathrm{~cm}$ ) in California Borderland sediments. In principle, one might envision attempting to correct the $\triangle \mathrm{DIC}$ results in Fig. 1 (where $\triangle \mathrm{DIC}$ is the difference in DIC concentration relative to the bottom water value) for DIC loss during carbonate precipitation using pore-water cation data (e.g., $\left[\mathrm{Ca}^{2+}\right]$ or $\left[\mathrm{Ca}^{2+}\right]+$ $\left[\mathrm{Mg}^{2+}\right]$ ), depending on the authigenic carbonate phase that precipitates in these sediments. However, using such an approach to obtain $r_{\mathrm{C}: \mathrm{S}}$ is made difficult by uncertainties in how the diffusion coefficient ratio in an equation such as Eq. 1 is defined for this corrected DIC. In the Discussion section (subsection "AOM in sediments"), we will describe another approach that allows us to quantitatively examine this problem, and which demonstrates that carbonate precipitation alone cannot explain the low values of $r_{\mathrm{C}: \mathrm{S}}$ observed in Santa Monica Basin sediments.

\section{Methods}

Sediment and bottom water samples were collected in July 2008 aboard the RV Point Sur from the central portion of Santa Monica Basin. Santa Monica Basin is an inner basin of the California Borderland with a maximum depth of $910 \mathrm{~m}$, and sill depth of $725 \mathrm{~m}$ (Gorsline 1992). The bottom sediments of the basin floor are laminated (Christensen et al. 1994) because of low dissolved oxygen in the bottom waters $\left(<10 \mu \mathrm{mol} \mathrm{O}_{2} \mathrm{~kg}^{-1}\right)$, which effectively eliminates benthic macrofauna in these sediments.

Sediment cores were recovered using a multicorer equipped with $9.5-\mathrm{cm}$-diameter core liners. Cores with an intact sediment-water interface (as indicated by clear overlying water) were immediately transferred into a refrigerated van and processed within $2-9 \mathrm{~h}$ of recovery. 


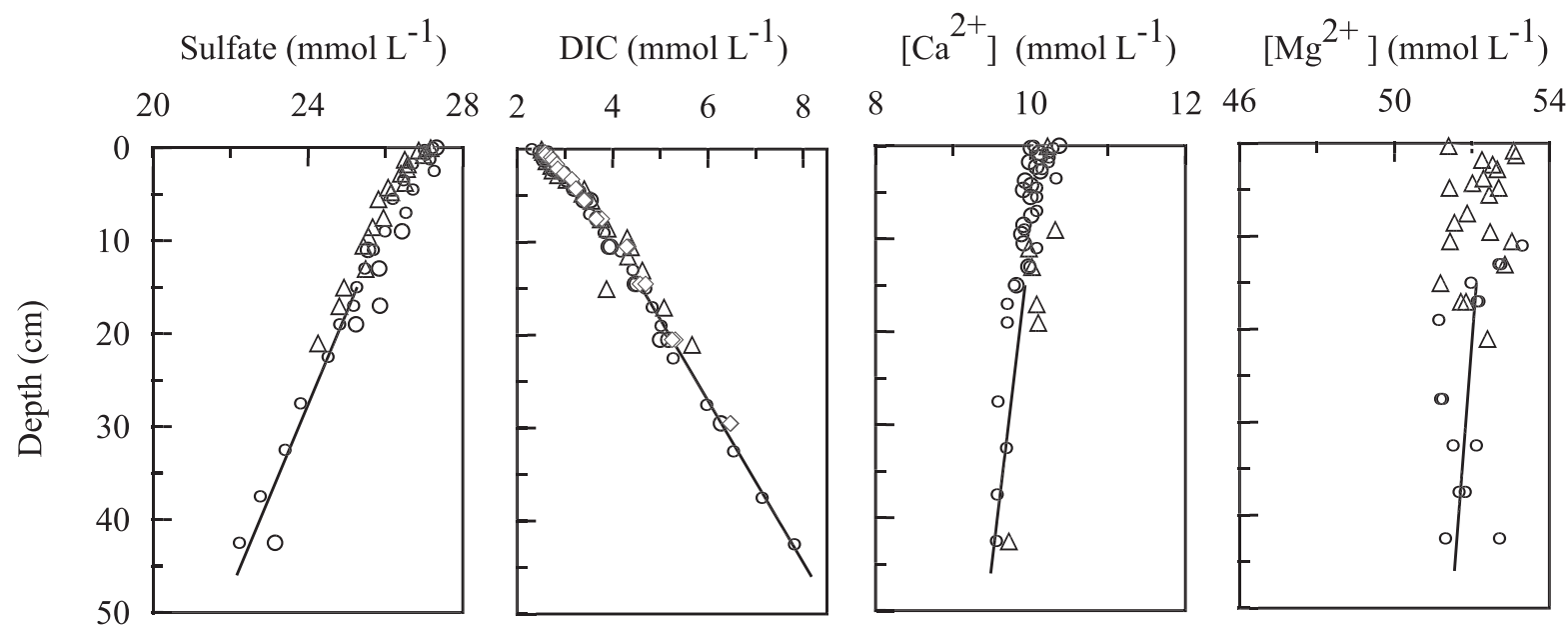

Fig. 2. Pore-water sulfate, DIC, $\mathrm{Ca}^{2+}$, and $\mathrm{Mg}^{2+}$ depth profiles from Santa Monica Basin sediments. Different symbols represent data from different cores, and the best-fit straight lines through the data below $15 \mathrm{~cm}$ were used to calculate the fluxes reported in Table 2 .

Bottom water samples were collected with a soap- and acidcleaned Go-Flo bottle.

In the refrigerated van, sediment cores were extruded in an $\mathrm{N}_{2}$ atmosphere at intervals of $0.25,0.5$, or $1 \mathrm{~cm}$ to a depth of $45 \mathrm{~cm}$. The outermost $0.5-\mathrm{cm}$ rind of each sediment slice was discarded to prevent effects from smearing. The sediments were placed in polycarbonate tubes and centrifuged at $4{ }^{\circ} \mathrm{C}$ at 8400 revolutions per minute for $20 \mathrm{~min}$. The supernatant was collected into an allpolypropylene syringe with a stainless steel needle and passed through a $0.2-\mu \mathrm{m}$ nylon disposable filter with a $0.7-$ $\mu \mathrm{m} \mathrm{GF} / \mathrm{F}$ prefilter (Whatman 6870-2502). The first $3 \mathrm{~mL}$ were discarded. DIC samples for concentration analyses were placed in $2-\mathrm{mL}$ serum vials with no headspace, immediately crimp-sealed, and stored refrigerated until analyzed (Burdige and Homstead 1994). Samples titrated on-board ship for total alkalinity were subsequently stored in plastic snap-cap tubes and refrigerated for shore-based analyses of $\mathrm{SO}_{4}^{2-}, \mathrm{Ca}^{2+}$, and $\mathrm{Mg}^{2+}$. Analyses of these samples were corrected for sample dilution by the acid used in the alkalinity titration. Additional pore-water samples for $\mathrm{SO}_{4}^{2-}, \mathrm{Ca}^{2+}$, and $\mathrm{Mg}^{2+}$ analyses were collected in plastic snap-cap tubes, acidified $\left(\sim 100 \mu \mathrm{L}\right.$ of $6 \mathrm{~mol} \mathrm{~L}^{-1} \mathrm{HCl}$ per $10 \mathrm{~mL}$ of sample), and refrigerated.

Pore waters from cores collected in this fashion, most particularly in deep-sea sediments (Emerson et al. 1982), can be subject to pressure artifacts in the analysis of inorganic carbon system parameters (e.g., DIC and alkalinity). However, several lines of evidence suggest that such pressure effects have a negligible effect on our porewater results. In studies of Santa Monica Basin (Jahnke 1990) and the nearby (and quite similar) San Pedro Basin (Berelson et al. 1987), in situ measured benthic fluxes of alkalinity and DIC show good agreement with fluxes calculated using pore-water profiles. Furthermore, in deepsea sediments $(>4 \mathrm{~km}$ water depth) where these pressure effects can be significant (Emerson et al. 1982), the observed effects are a strong function of sediment carbonate (inorganic carbon [IC]) content. The sediments in Santa Monica Basin are 1\% IC (T. Komada unpubl.), and given their relatively "shallow" water depth $(900 \mathrm{~m})$, the observations in Emerson et al. (1982) further suggest that any pressure effects here on the analysis of inorganic carbon system parameters are likely to be minimal.

Concentrations of DIC were determined by flow injection analysis (Hall and Aller 1992; Lustwerk and Burdige 1995), $\mathrm{SO}_{4}^{2-}$ was determined by ion chromatography, and $\mathrm{Ca}^{2+}$ was determined by automated titration with ethylene glycol tetraacetic acid as a complexing agent and a $\mathrm{Ca}$ ion-selective electrode for end-point detection (Burdige et al. 2008). $\mathrm{Mg}^{2+}$ was determined by inductively coupled plasma optical emission spectrometry in the lab of R. Sherrell at Rutgers University.

All plastic and metal tools and parts were first washed with soap, then acid washed, rinsed with deionized water, and air dried. Glassware was washed in the same manner and then ashed at $550^{\circ} \mathrm{C}$ for $4 \mathrm{~h}$.

\section{Results}

Figure 2 presents pore-water DIC, sulfate, $\mathrm{Ca}^{2+}$, and $\mathrm{Mg}^{2+}$ depth profiles in the upper $\sim 40 \mathrm{~cm}$ of Santa Monica Basin sediments. In the upper $\sim 5-10 \mathrm{~cm}$ of sediment, curvature in the pore-water sulfate and DIC profiles (along with pore-water ammonium and alkalinity profiles not shown here) indicates the occurrence of organic matter remineralization (sulfate reduction) producing or consuming these solutes. Below $\sim 10-20 \mathrm{~cm}$, the profiles are remarkably linear, which is often interpreted as being indicative of a diffusion zone that separates reactions occurring in the surface $\sim 5-10 \mathrm{~cm}$ of sediment and those in a second reaction zone deeper in the sediments (for details, see below and Berelson et al. 2005). Although our model results below suggest that this might not always strictly be the case (see subsection "Case 3: Low reactive POC flux, no methanogenesis, external methane flux from below"), this assumption is adequate for the discussion in this section. 
Table 1. Model parameters.

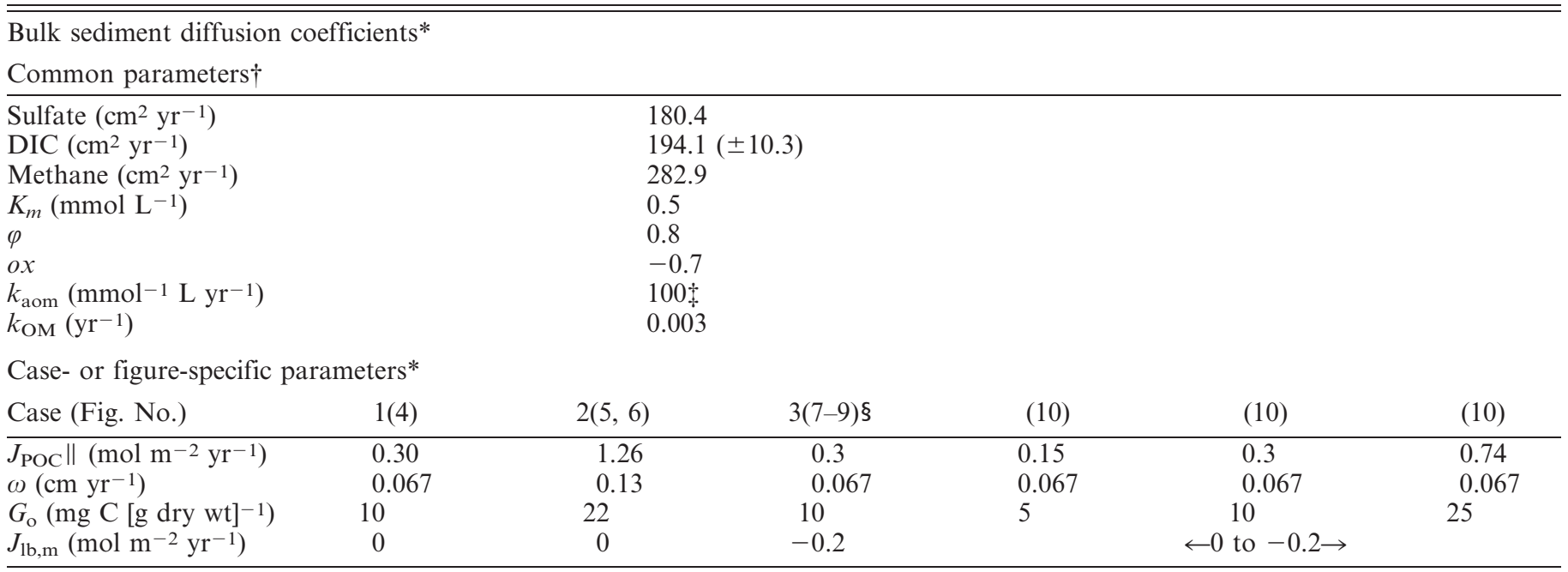

* Seawater-free solution diffusion coefficients $\left(D^{\circ}\right)$ were obtained from Schulz and Zabel (2006) for an assumed bottom water temperature of $5^{\circ} \mathrm{C}$. The free solution diffusion coefficient for DIC is a weighted average of the diffusion coefficients for $\mathrm{HCO}_{3}^{-}, \mathrm{CO}_{3}^{2-}$, and aqueous $\mathrm{CO}_{2}$ based on their relative average composition $( \pm 1 \sigma)$ in pore-water DIC from Santa Monica Basin sediments $\left(93.7 \% \pm 2.8 \%, 3.8 \% \pm 3.5 \%\right.$, and $3.5 \% \pm 2.1 \%$, respectively). $D^{\circ}$ values were corrected for sediment tortuosity to obtain the bulk sediment diffusion coefficients listed here using the modified Weissberg equation to parameterize sediment tortuosity. This results in $D_{\mathrm{s}}=D^{\circ} /\left[1-\ln \left(\varphi^{2}\right)\right]$ (Boudreau 1997).

$\uparrow$ All parameters are defined in the text.

\$ In some model runs (not shown here), increasing $k_{\text {aom }}$ to $1000 \mathrm{mmol}^{-1} \mathrm{~L} \mathrm{yr}^{-1}$ or decreasing it to $10 \mathrm{mmol}^{-1} \mathrm{~L} \mathrm{yr}^{-1}$, with other parameters held constant, had no effect on the model output.

$\S$ These are the case 3 base run parameters. In other case 3 runs, $J_{\mathrm{lb}, \mathrm{m}}$ or $J_{\mathrm{POC}}$ were varied as discussed in Tables 3 and 4.

"In the absence of bioturbation $J_{\mathrm{POC}}=(1-\varphi) \omega \rho_{\mathrm{ds}} G_{\mathrm{o}}$.

In other studies, it has been suggested that linear sulfate profiles similar to those seen here could be the result of a balance between sulfate reduction and either sulfide oxidation or pore-water sulfate replenishment, both possibly driven by low rates of bioirrigation into deep anoxic sediments (Fossing et al. 2000; Dale et al. 2008; Jørgensen and Parkes 2010). However, in many California Borderland basins, including Santa Monica Basin, low bottom water $\mathrm{O}_{2}$ levels preclude macrofaunal colonization of the sediments (see "Methods" for details) and therefore argue against this explanation here.

Where pore-water profiles appeared highly linear, diffusive fluxes $(J)$ into or out of the deeper sediments were calculated with the equation

$$
J=-\varphi D_{\mathrm{s}} \frac{\partial C}{\partial z}
$$

The concentration gradient $d C l d z$ was obtained by a linear least-squares fit to the pore-water data below $15 \mathrm{~cm}$, the bulk sediment diffusion coefficients $\left(D_{\mathrm{s}}\right)$ were determined as described in Table 1 (footnote $*$ ), and the sediment porosity at depth was taken to be $0.84 \pm 0.05$ (T. Komada unpubl.; Huh et al. 1987; Christensen et al. 1994). These linear gradients are shown in Fig. 2 and are listed, along with the diffusive fluxes, in Table 2.

\section{Discussion}

AOM in sediments-Diffusive fluxes based on the gradients in Table 2 represent the depth-integrated rates of solute production or consumption deeper in the sediment column. The ratio of the upward DIC flux to the downward sulfate flux below $\sim 15 \mathrm{~cm}$ in these sediments is $1.23 \pm 0.2$ (Table 2), consistent with the estimate of $r_{\mathrm{C}: \mathrm{S}}$ for the entire sediment profile based on the DIC : sulfate property-property plot in Fig. 1. However as noted above, these estimates of $r_{\mathrm{C}: \mathrm{S}}$ are intermediate between that predicted for sulfate reduction coupled to organic matter oxidation in the surface sediments (referred to here as OMX), which is expected to be $\sim 1.8-1.7$

Table 2. Diffusive fluxes at depth in Santa Monica Basin sediments.

\begin{tabular}{lcr}
\hline \hline \multicolumn{1}{c}{ Solute } & $\begin{array}{c}\text { Gradient } \\
\left(\mathrm{mmol} \mathrm{L}^{-1} \mathrm{~cm}^{-1}\right)^{*}\end{array}$ & \multicolumn{1}{c}{$\begin{array}{c}\text { Flux } \\
\left(\mathrm{mol} \mathrm{m}^{-2} \mathrm{yr}^{-1}\right) \dagger\end{array}$} \\
\hline Sulfate $\left(J_{\mathrm{lb}, \mathrm{s}}\right)$ & $-0.100 \pm 0.010$ & $0.113 \pm 0.015$ \\
$\mathrm{DIC}\left(J_{\mathrm{lb}, \mathrm{c}}\right)$ & $0.115 \pm 0.006$ & $-0.139 \pm 0.015$ \\
$\mathrm{Ca}^{2+}\left(J_{\mathrm{lb}, \mathrm{Ca}}\right)$ & $-0.014 \pm 0.002$ & $0.012 \pm 0.002$ \\
$\mathrm{Mg}^{2+}\left(J_{\mathrm{lb}, \mathrm{Mg}}\right)$ & $-0.018 \pm 0.008$ & $0.014 \pm 0.006$ \\
$J_{\text {deep,C }}^{\dagger}$ & & $0.151 \pm 0.017$ \\
& & $0.165 \pm 0.024$ \\
\hline
\end{tabular}

* Gradients are based on a linear fit to all pore-water data below $15 \mathrm{~cm}$ (see Fig. 2). Positive gradients (and fluxes) are downward.

$\uparrow$ Fluxes were calculated with Eq. 5 as discussed in the text. Errors are $1 \sigma$ and we propagated through these calculations using standard techniques.

$\$ J_{\text {deep,C }}$ is the gross integrated rate of DIC production in the deep sediments (i.e., the upward DIC flux corrected for carbonate precipitation at depth). The upper value assumes that authigenic carbonate precipitation involves only $\mathrm{Ca}^{2+}$ uptake at depth, and $J_{\mathrm{deep}, \mathrm{C}}=J_{\mathrm{lb}, \mathrm{C}}-$ $J_{\mathrm{lb}, \mathrm{Ca}}$. The lower value assumes that both $\mathrm{Ca}^{2+}$ and $\mathrm{Mg}^{2+}$ precipitate as authigenic carbonates at depth, and $J_{\mathrm{deep}, \mathrm{C}}=J_{\mathrm{lb}, \mathrm{C}}-J_{\mathrm{lb}, \mathrm{Ca}}-J_{\mathrm{lb}, \mathrm{Mg}}($ see the text for further details). 
corresponding to remineralization of organic matter assumed to have an $o x$ value of -0.5 to -0.7 , and AOM, which has an $r_{\mathrm{C}: \mathrm{S}}$ value of 1 and, as we will show below, is an important process in the deeper parts of these sediments.

To explore the factors that are responsible for this flux ratio in Santa Monica Basin sediments (and by inference the apparent $r_{\mathrm{C}: \mathrm{S}}$ ratio based on pore-water property-property plots), we first note that extrapolation of the linear portion of the sulfate profile to zero sulfate concentration yields a sediment depth of $\sim 2.5 \mathrm{~m}$. The region in the sediments where this occurs is often referred to as the sulfate-methane transition zone (SMTZ), and methane concentrations generally begin to build up below the SMTZ once sulfate is depleted. Possible sources of this methane are discussed in the next section. The SMTZ also generally represents the region in the sediments where AOM occurs at its highest rates (Knab et al. 2008; Alperin and Hoehler 2009). In coastal sediments, the SMTZ occurs at depths of tens of centimeters (Goldhaber et al. 1977; Alperin et al. 1992; Martens et al. 1992); in inner continental margin sediments, it occurs at depths of 1-5 m (Niewöhner et al. 1998; Berelson et al. 2005; Dale et al. 2008; Harrison et al. 2009), and in outer continental margin sediments, it occurs at depths of tens of meters or more (Borowski et al. 1999; Dickens 2001).

Using the fluxes derived from the linear gradients shown in Fig. 2, we can re-examine the possible role of carbonate precipitation in the observed $r_{\mathrm{C}: \mathrm{S}}$ value for Santa Monica Basin sediments. To do this, we initially correct the DIC flux at the base of our profiles $\left(J_{1 \mathrm{~b}, \mathrm{C}}\right)$ for carbonate precipitation in two ways: in the first we assume that the linear $\mathrm{Ca}^{2+}$ gradient is the result of uptake at depth into authigenic carbonates (Berelson et al. 2005) and that the $\mathrm{Mg}^{2+}$ gradient is associated with uptake into noncarbonate (i.e., clay mineral) phases (Sholkovitz 1973; Leslie et al. 1990). In the second case, we assume that the $\mathrm{Ca}^{2+}$ and $\mathrm{Mg}^{2+}$ gradients both reflect uptake into carbonate phases (Tipper et al. 2006; Higgins and Schrag 2010). Either of these corrections accounts for DIC loss due to carbonate precipitation, yielding the integrated gross rate of DIC production in the deeper sediments $\left(J_{\text {deep,C }}\right)$. Estimates of $J_{\text {deep,C }}$ are also listed in Table 2 .

A comparison of $J_{\text {deep,C }}$ to $J_{\mathrm{lb}, \mathrm{S}}$, the downward sulfate flux, which also equals the depth-integrated rate of sulfate reduction in the deep sediments, yields a ratio of $1.34 \pm$ 0.23 to $1.46 \pm 0.25$, depending on which type of authigenic carbonate is assumed to precipitate. This range of values is intermediate between the expected $r_{\mathrm{C}: \mathrm{S}}$ value for OMX (= 1.7-1.8, depending on the value of $o x)$ and AOM $(=1)$. Thus, carbonate precipitation does affect the apparent $r_{\mathrm{C}: \mathrm{S}}$ value determined with pore-water data from Santa Monica Basin sediments, and future studies are needed to better define the type of authigenic carbonate precipitation that occurs in these sediments. Nevertheless, it also appears that authigenic carbonate precipitation alone cannot explain the observed deviations in the $r_{\mathrm{C}: \mathrm{S}}$ ratio from expected values. Rather, this calculation suggests that sulfate reduction coupled to both OMX and AOM in the deep part of Santa Monica Basin sediments must together be responsible for the low apparent $r_{\mathrm{C}: \mathrm{S}}$ value seen in these sediments.
These depth-integrated rates can next be used to examine the relative importance of OMX and AOM at depth in Santa Monica Basin sediments. In this calculation, we apportion the gross DIC production in the deep sediments to AOM and OMX according to

$$
J_{\text {deep,C }}=J_{\text {deep,AOM }}+J_{\text {deep,OMX }}
$$

Similarly, the sulfate flux at the lower boundary of the profiles must be balanced by consumption through AOM and OMX in the deep sediments. On the basis of the value of $o x$ and the stoichiometry of OMX and AOM, as indicated by Eqs. 3 and 4, this implies that,

$$
-J_{\mathrm{lb}, \mathrm{S}}=J_{\text {deep,AOM }}+\frac{1}{r_{\mathrm{C}: \mathrm{S}}} J_{\text {deep,OMX }}
$$

and combining these equations yields

$$
J_{\text {deep }, \text { OMX }}=\frac{J_{\text {deep }, \mathrm{C}}+J_{\text {lb,S }}}{1-\left(1 / r_{\mathrm{C}: \mathrm{S}}\right)}
$$

On the basis of the results shown in Table 2 , if $o x=$ -0.7 to -0.5 , then OMX accounts for $\sim 60-80 \%$ of the gross integrated rate of DIC production in deep Santa Monica Basin sediments, with AOM accounting for the remaining $\sim 20-40 \%$. Calculations presented in Berelson et al. (2005) for four other Borderland basins (Santa Barbara, Soledad, Alfonso, and Pescadero) yield almost identical values for the relative contributions of OMX and AOM in the deeper portions of these basin sediments (OMX, 7090\%; AOM, 10-30\%).

The methane that drives the observed AOM in these continental margin sediments could have two possible sources (Fig. 3). One is in situ methanogenesis, which, based on the biogeochemical zonation model, occurs after the depletion of sulfate in the pore waters (Burdige 2006). Here, organic matter initially deposited at the sediment surface and subsequently buried by sediment accumulation is remineralized by methanogens to $\mathrm{CO}_{2}$ and $\mathrm{CH}_{4}$. In most sediments in which molecular diffusion is the main transport mechanism for methane, the upward methane flux driven by this methanogenesis is nearly quantitatively oxidized by AOM at the base of the sulfate reduction zone, such that there is little net methane loss from the sediments (see Reeburgh 2007, for a recent review).

However, another source of methane to some continental margin sediments may be an "external" source not directly coupled to present-day organic carbon deposition and burial and in situ methanogenesis. These sources might include geologic hydrocarbon reservoirs derived from ancient source rocks, or deeply buried gas hydrate deposits. Such deposits are common in many continental margin settings (Milkov and Sassen 2002; Zhang and Lanoil 2004), including Santa Monica Basin. Here, seismic reflection profiles indicate the presence of gas reservoirs at least $200 \mathrm{~m}$ below the seafloor (Normark et al. 2006), and upward migration of gas from these deposits results in the formation of gas hydrate deposits as shallow as $\sim 1.5-2 \mathrm{~m}$ below the seafloor (Hein et al. 2006; Paull et al. 2008). Similar types of gas migration are also common in other continental margin sediments (Milkov and Sassen 2002). 


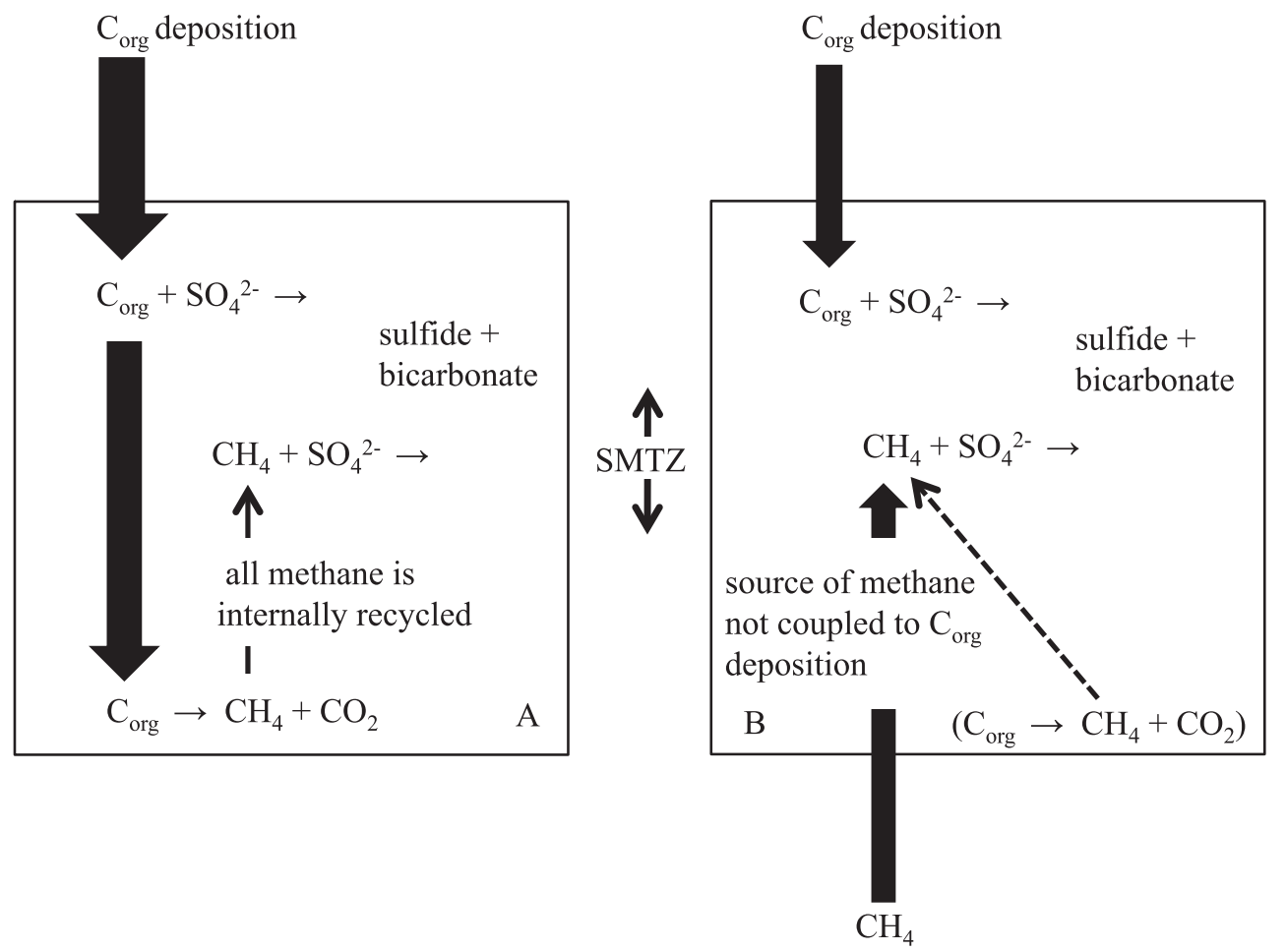

Fig. 3. An illustration of two possible scenarios for the input of methane that drives AOM in marine sediments. Note that (B) has two sources of reduced carbon to the sediments that drive the observed microbial remineralization processes, whereas (A) has only one source.

The fact that we can think about such a deep methane source as being uncoupled from contemporaneous surface organic carbon fluxes and any associated in situ methanogenesis will be an important aspect of the subsequent discussion.

Development and implementation of a numerical AOMOMX model-To more directly examine the linkages between the sources of methane that drive AOM in marine sediments and the observed values of $r_{\mathrm{C}: \mathrm{S}}$ based on porewater property-property plots, we use the following steadystate sediment reactive-transport model. It should be noted that the goal here is not to specifically simulate processes taking place in Santa Monica Basin sediments, but rather to explore the linkages between AOM and values of $r_{\mathrm{C}: \mathrm{S}}$ in a more general context.

The model consists of a set of equations for pore-water sulfate $(S)$, methane $(M)$, and DIC $(C)$, and reactive particulate organic carbon (POC) in the sediments $(G)$ and considers the following processes: diffusion $(S, M$, and $C)$, sedimentation $(G)$ or pore-water solute advection driven by sedimentation $(S, M$, and $C)$, reactive POC remineralization by bacterial sulfate reduction $(S, G$, and $C)$ and methanogenesis $(G, C$, and $M)$, and anaerobic methane oxidation $(S, M$, and $C$ ). For the sake of simplicity, we do not consider the occurrence of other organic matter remineralization processes (e.g., aerobic respiration) or other secondary reactions such as sulfide oxidation or carbonate mineral precipitation or dissolution. We also assume that porosity is constant with sediment depth.
In the model, we assume that only one "type" of organic matter is undergoing remineralization in the sediments (i.e., we use a 1-G model). Many, but not all, other modeling studies, use a multi- $G$ approach (e.g., Westrich and Berner 1984), often assuming that there are two to three types (or fractions) of organic matter undergoing remineralization (Burdige 2006). Although future versions of this model will incorporate a multi- $G$ approach, the use of a 1- $G$ model does not affect the major conclusions of the work presented here.

These considerations result in the following equations,

$$
\begin{aligned}
0= & D_{s} \frac{\partial^{2} S}{\partial z^{2}}-\omega \frac{\partial S}{\partial z}-\frac{k_{O M} L_{1} F G S}{K_{m}+S}-k_{a o m} S M \\
0= & -\omega \frac{\partial G}{\partial z}-\frac{k_{\mathrm{OM}} G S}{K_{m}+S}-f_{\mathrm{S}} k_{\mathrm{OM}} G \\
0= & D_{m} \frac{\partial^{2} M}{\partial z^{2}}-\omega \frac{\partial M}{\partial z}+f_{\mathrm{S}} k_{\mathrm{OM}} L_{2} F G-k_{\mathrm{aom}} S M \\
0= & D_{\mathrm{C}} \frac{\partial^{2} C}{\partial z^{2}}-\omega \frac{\partial C}{\partial z}+\frac{k_{\mathrm{OM}} F G S}{K_{m}+S} \\
& +f_{\mathrm{S}} k_{\mathrm{OM}} L_{3} F G+k_{\mathrm{aom}} S M
\end{aligned}
$$

In these equations $\omega$ is the sediment accumulation rate and the rate of pore-water advection driven by sedimentation, since we have assumed that sediment porosity is constant with depth; $k_{i}$ is the rate constant for organic matter 
degradation $(i=\mathrm{OM})$ or $\mathrm{AOM}(i=\mathrm{aom}) ; F$ is a factor that converts solid-phase concentration units to pore-water solute concentration units (Burdige 2006); and $K_{m}$ is the half-saturation constant for sulfate reduction. In addition,

$L_{1}=$ moles sulfate reduced :

$$
\text { mole POC oxidized }\left(=1 / r_{\mathrm{C}: \mathrm{S}}\right)
$$

$L_{2}=$ moles methane produced :

$$
\text { mole POC oxidized }=(4-o x) / 8
$$

$L_{3}=$ moles DIC produced (during methanogenesis) :

$$
\text { mole POC oxidized }=(4+o x) / 8
$$

These three terms modify the stoichiometric coefficients for sulfate reduction and methanogenesis based on the carbon oxidation state of the reactive POC being remineralized. The derivation of Eqs. $13 \mathrm{~b}$ and $13 \mathrm{c}$ is presented below. The function $f_{\mathrm{S}}$ inhibits the occurrence of methanogenesis when sulfate concentrations are above some threshold value (Dhakar and Burdige 1996; Martens et al. 1998). A number of formulations for functions such as this have been reported in the literature. Here we used,

$$
f_{\mathrm{S}}=\frac{10^{-5}}{10^{-5}+S}
$$

which effectively inhibits the occurrence of methanogenesis $\left(f_{\mathrm{S}}=0\right)$ when sulfate is present $\left(S>\sim 10^{-3} \mathrm{mmol} \mathrm{L}^{-1}\right)$.

The upper boundary condition for the model equations specifies the sulfate, DIC, and methane concentrations at the sediment-water interface ( 0 for methane, bottom water values for the other two solutes), and fixes the reactive POC concentration at the sediment surface $\left(G_{o}\right)$. At the lower boundary of the model (i.e., $z \rightarrow \infty$ ), we specify that $\partial S / \partial z$ and $\partial C / \partial z$ go to zero. For methane, we specify that $\partial M / \partial z$ goes to zero as $z \rightarrow \infty$ if we assume there is no upward flux of methane into the sediments from an external source. For model runs in which we want to proscribe an upward flux of methane into the sediments $\left(J_{1 \mathrm{~b}, \mathrm{~m}}\right)$ at the lower boundary, we use the following boundary condition,

$$
J_{\mathrm{lb}, \mathrm{m}}=-\varphi D_{\mathrm{m}} \frac{\partial M}{\partial z}
$$

In all model calculations, depth is positive downward, and therefore negative fluxes are upward toward the sediment surface.

Equations 9-12 represent a set of coupled, nonlinear differential equations, for which there is no analytical solution. A solution to this set of equations was obtained numerically using the Method of Lines technique with variable grid spacing (Schiesser 1991; Boudreau 1997). The spatial domain of the solution (defined here from 0 to $L$ ) was first subdivided by $n$ grid points (generally $\sim 200$ ), distributed such that the $\Delta z_{i}$ value between grid points increased as depth increased (having a finer grid spacing near the sediment-water interface allows one to more accurately represent concentration profiles and gradients in this region of the sediments where these parameters often show rapid changes). At each grid point, the first and second derivatives of sulfate, methane, and DIC concentration were approximated using centered, finite-difference approximations (see either of the references above for details). The first derivative of reactive POC in Eq. 10 was approximated using a backward difference approximation. With this approach, Eqs. 9-12 were transformed from space- and time-dependent partial differential equations into a set ( $4 n$ total) of time-dependent ordinary differential equations (ODEs) valid at each of the $n$ grid points. This set of coupled, nonlinear ODEs was solved in MATLAB using the integration package ode15s. The stiffness of this set of ODEs is well handled by this integration package. A copy of the complete MATLAB script used to solve these equations is available from the first author.

Solving these equations using the Method of Lines actually results in a time-dependent solution to the individual model equations (concentration vs. depth vs. time), although here, only steady-state solutions are presented. The model was generally run forward in time for $\sim 10,000 \mathrm{yr}$, although a steady state was reached after $\sim 8000 \mathrm{yr}$ or less, depending on the set of initial conditions used to start the model run. Model runs were carried out to a maximum sediment depth of between 300 and $600 \mathrm{~cm}$ using parameters listed in Table 1. In any given model run, internal mass balance for sulfate or carbon (e.g., depthintegrated loss of reactive POC plus upward methane flux vs. depth-integrated rate of DIC production; depthintegrated sulfate reduction rate vs. benthic flux of sulfate into the sediments) generally agreed to within $1 \%$ or less and sometimes to within $0.5 \%$ or less.

To test the accuracy of the numerical model, we ran the model with $K_{m}=0, G_{\mathrm{o}}=15 \mathrm{mg} \mathrm{C}(\mathrm{g} \text { dry wt })^{-1}$ and $J_{\mathrm{lb}, \mathrm{m}}=$ 0 , with all other model parameters as listed in Table 1 for case 1 sediments. Under these conditions, reactive POC is depleted before pore-water sulfate (e.g., Fig. 4), and hence, there is no methanogenesis and no occurrence of AOM. With $K_{m}=0$, the kinetics of bacterial sulfate reduction are also simplified so that the process is now independent of sulfate concentration (see Eq. 19), and Eqs. 9, 10, and 12 can be solved analytically (Burdige 2006). There was excellent agreement between the numerical model results and the analytical solutions for $G, S$, and $C$, with the normalized root mean square error for the two sets of solutions being $<1 \%$.

Derivation of eqs. $13 \mathrm{~b}$ and $13 \mathrm{c}$-Using the approach described in Burdige (2006), we assume here that organic matter of oxidation state $o x$ is reduced to methane and oxidized to $\mathrm{CO}_{2}$ during methanogenesis. Production of $1 \mathrm{~mol}$ of methane from this POC requires $4+o x \mathrm{~mol}$ of electrons, whereas $\mathrm{CO}_{2}$ production yields $4-o x$ mol of electrons per mole of POC oxidized. Next we write the equation for methanogenesis as,

$$
\mathrm{POC} \rightarrow L_{3} \mathrm{CO}_{2}+L_{2} \mathrm{CH}_{4}
$$

where $L_{2}$ and $L_{3}$ are defined above, and for simplicity, we 


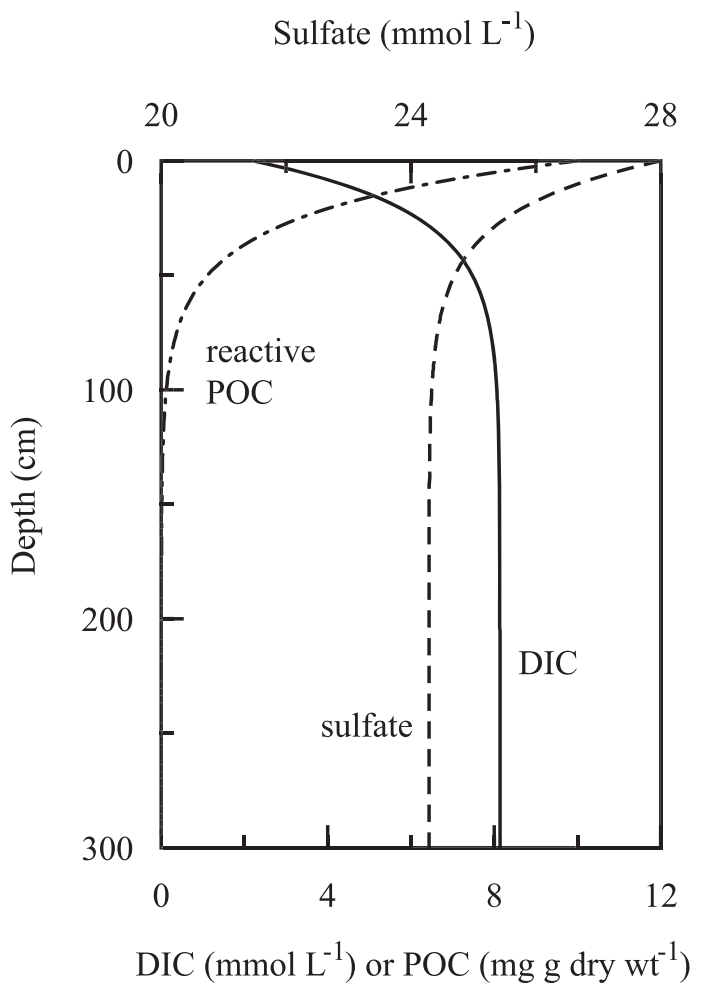

Fig. 4. Model-derived sediment profiles for a case 1 sediment, in which there is a low reactive POC flux $(0.3 \mathrm{~mol}$ $\mathrm{C} \mathrm{m}^{-2} \mathrm{yr}^{-1}$ ), no methanogenesis, and no external input of methane at depth. The parameters used for this model calculation are listed in Table 1.

have not completely balanced this equation. Electron balance and carbon mass balance now requires that,

$$
\begin{gathered}
L_{2}(4+o x)=L_{3}(4-o x) \\
L_{2}+L_{3}=1
\end{gathered}
$$

and the solution of these two equations yields Eqs. 13b and $13 \mathrm{c}$.

Model results-In the model results described here, we have primarily focused on the effects of (1) changing the carbon loading (or rain rate) to the sediments, using values that are typical of continental margin sediments; (2) the presence or absence of an upward, external methane flux at the lower model boundary; and (3) the magnitude of this flux, when present. The methane fluxes used in our calculations are within the range of values reported by Berelson et al. (2005) for California Borderland basin sediments. In all model runs, $o x$ was set equal to -0.7 ; therefore, the expected value of $r_{\mathrm{C}: \mathrm{S}}$ is 1.7.

Case 1: Low reactive POC flux, no methanogenesis, no external methane flux: Here carbon loading to the sediments is sufficiently low that reactive POC is depleted before pore-water sulfate; hence, there is no methanogenesis. Model results yield depth profiles of reactive POC, sulfate, and DIC that decrease (POC, sulfate) or increase (DIC) in exponential-like fashions (Fig. 4). These trends are broadly consistent with field results from many nearshore sediments (Burdige 2006) and are consistent with the analytical solution to the "simplified" forms of Eqs. 9, 10, and 12 discussed in the previous section, where $K_{\mathrm{m}}$ was set to 0 . This agreement is not surprising because, when sulfate values are high $(>20 \mathrm{mM}$ in these model runs), $S \gg K_{\mathrm{m}}$, and the rate expression for sulfate reduction essentially becomes independent of sulfate concentration; that is,

$$
\frac{k_{\mathrm{OM}} G S}{K_{m}+S} \approx k_{\mathrm{OM}} G
$$

as also occurs if $K_{\mathrm{m}}$ is specifically set equal to 0 . The DIC:sulfate property-property plot with the case 1 numerical model results (not shown here) yields the expected $r_{\mathrm{C}: \mathrm{S}}$ value of 1.7 .

Case 2: In situ methanogenesis, no external methane flux: With an increase in sediment carbon loading, complete sulfate depletion occurs in the sediments along with in situ methanogenesis. An example of one such model run for this case is shown in Fig. 5. Overall, model-derived methane profiles are concave-up, as is seen in many marine sediments (Reeburgh 2007), although the methane gradient just below the SMTZ is highly linear. Model-derived sulfate profiles similarly show curvature over the entire depth range of the profile, consistent with that seen in many marine sediments, although, again, the sulfate gradient into the SMTZ is linear.

In real sediments where diffusion is the dominant mode of pore-water transport, methane and sulfate pore-water profiles just above (sulfate) and below (methane) the SMTZ are indeed often linear (Niewöhner et al. 1998; Berelson et al. 2005), and the ratio of their diffusive fluxes into the SMTZ is expected to be 1 if AOM is the sole mode of sulfate reduction in this zone (see Eq. 4). Although such values are often seen, higher flux ratios have also been observed, with one possible explanation for this being the co-occurrence of AOM and sulfate reduction coupled to OMX in the SMTZ (Berelson et al. 2005; Jørgensen and Parkes 2010).

In the results shown in Fig. 5, the ratio of the downward diffusive sulfate flux into the SMTZ to the upward methane flux is 1.36 because sulfate reduction coupled to OMX also occurs in the SMTZ, and AOM accounts for only 17\% of the total sulfate reduction. Increasing the carbon loading to these case 2 sediments by $20 \%$ (i.e., $G_{\mathrm{o}}$ is increased from 22 to $26.4 \mathrm{mg} \mathrm{C}$ (g dry wt) ${ }^{-1}$ with $\omega$ unchanged) increases the relative importance of AOM to total sulfate reduction to $31 \%$ and therefore decreases this flux ratio to 1.16 .

Of greater interest, though, is that, for case 2 sediments, the DIC: sulfate property-property plot (Fig. 6) yields an $r_{\mathrm{C}: \mathrm{S}}$ value of 1.7. Thus, despite the occurrence of AOM in the model sediments, the property-property plot of these model results returns the value of $r_{\mathrm{C}: \mathrm{S}}$ for OMX coupled to sulfate reduction. This then leads to the important conclusion that the internal cycling of methane by in situ 

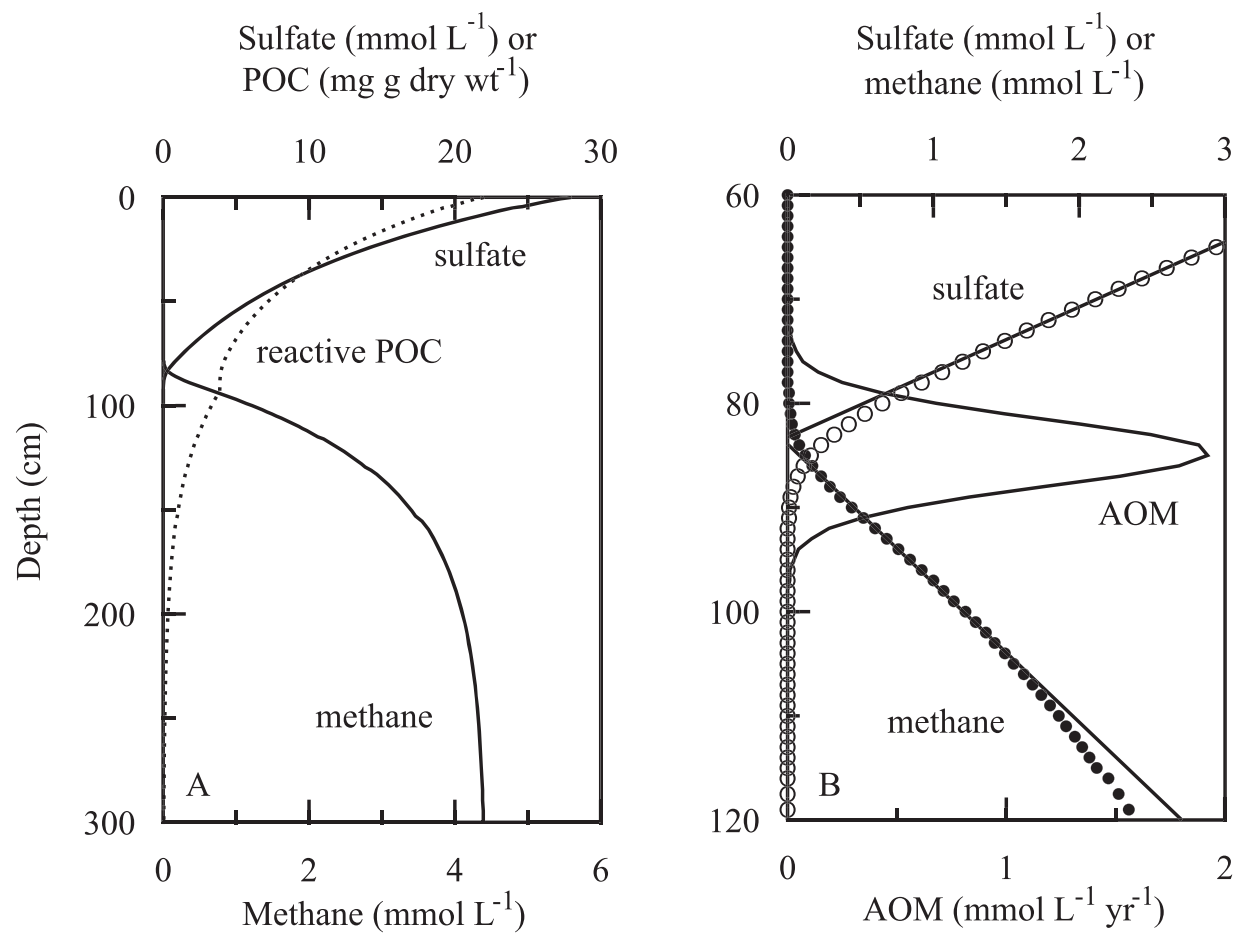

Fig. 5. (A) Model-derived sediment profiles for a case 2 sediment, in which the reactive POC flux $\left(1.26 \mathrm{~mol} \mathrm{C} \mathrm{m} \mathrm{m}^{-2} \mathrm{yr}^{-1}\right)$ is high enough that methanogenesis occurs at depth, with no deep external input of methane. The parameters used for this model calculation are listed in Table 1 . Note that the kink in the reactive POC profile near the base of the sulfate reduction zone is a model artifact that results from the way the function $f_{\mathrm{s}}$ (Eq. 14) inhibits methane production in the presence of sulfate. (B) An expanded view of the sulfate, methane, and AOM rate profiles around the SMTZ. The best-fit straight lines through the sulfate and methane data predict a value of $1.36 \pm 0.02$ for the sulfate: methane diffusive flux ratio into the SMTZ $\left(=J_{\mathrm{lb}, \mathrm{s}} / J_{\mathrm{lb}, \mathrm{m}}\right)$. Symbols here indicate individual model data points.

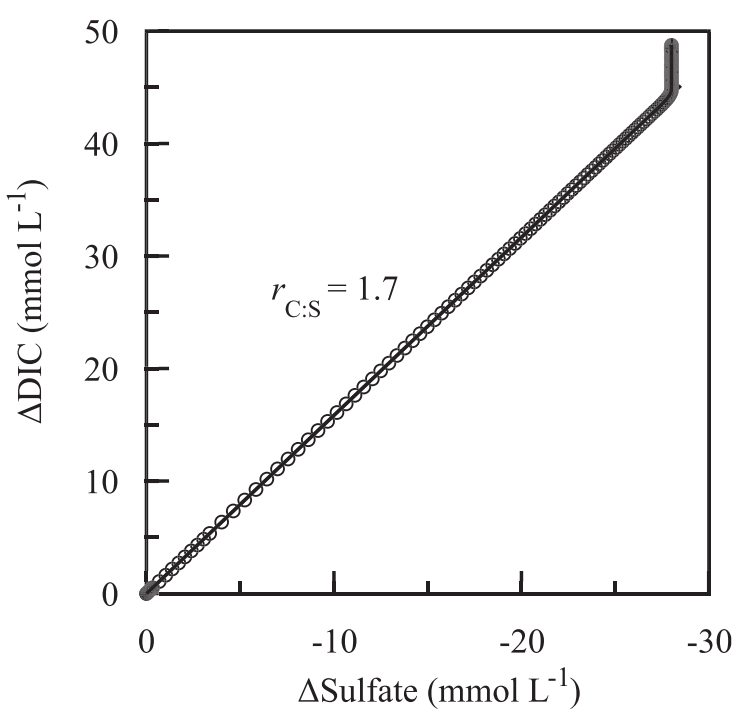

Fig. 6. The DIC: sulfate property-property plot for the case 2 model results shown in Fig. 5. The value of $r_{\mathrm{C}: \mathrm{S}}$ was determined using a fit to the model data (open circles) solely from the zone of sulfate reduction (i.e., where $S>0$ or $\Delta$ sulfate $<-28$ ). methanogenesis and AOM will not lead to deviations in the value of $r_{\mathrm{C}: \mathrm{S}}$ such as those seen in many continental margin sediments (e.g., see Fig. 1 and the discussion at the beginning of the introduction section). Also note that this observation is independently verified with calculations discussed at the end of the subsection "Application of an analytical model to the examination of DIC: sulfate property-property plots.” Jørgensen and Parkes (2010) reached a similar conclusion based on an examination of the equations for methanogenesis and AOM, recognizing that the sum of these two reactions looks simply like sulfate reduction coupled to organic matter oxidation and assuming a tight coupling between the two processes. The model results shown here quantitatively verify their suggestion and further indicate that this coupling occurs despite the fact that the major zones of methane production and consumption in the sediments are spatially separated. For example, in the model results shown in Fig. 5, 98\% of the AOM occurs in a relatively narrow zone between the sediment depths of $\sim 76$ and $93 \mathrm{~cm}$, just above the much broader sediment region between 94 and $\sim 280 \mathrm{~cm}$, where methanogenesis occurs. 
Sulfate, methane or DIC (mmol L-1)
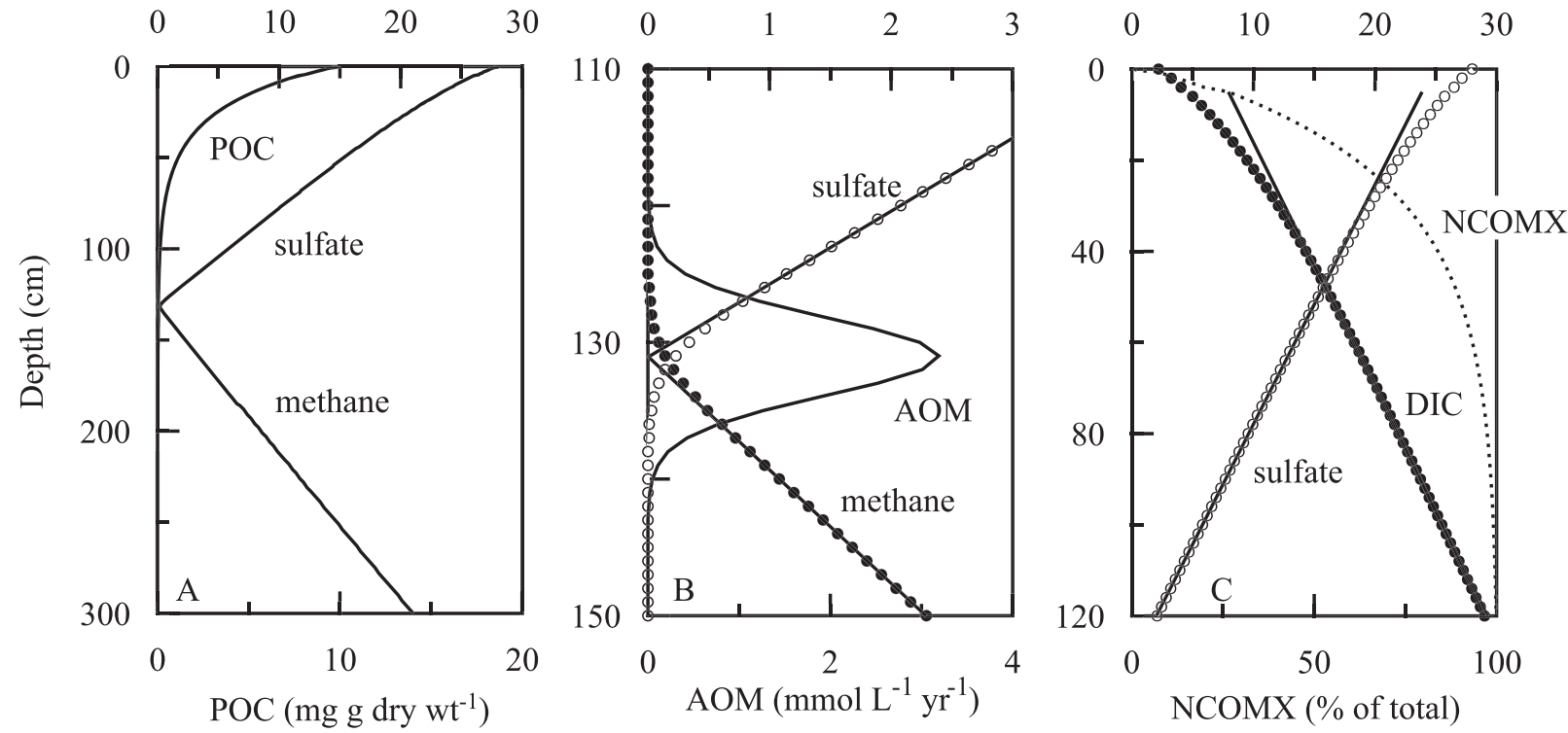

Fig. 7. (A) Model-derived sediment profiles for a case 3 sediment in which there is a high reactive POC flux $\left(0.3 \mathrm{~mol} \mathrm{C} \mathrm{m}^{-2} \mathrm{yr}^{-1}\right), \mathrm{no}^{-}$ in situ methanogenesis, and a deep external upward methane flux $\left(-0.2 \mathrm{~mol} \mathrm{C} \mathrm{m}^{-2} \mathrm{yr}^{-1}\right)$. The other parameters used in this model calculation are listed in Table 1 (case 3 base run). (B) An expanded view of the sulfate, methane, and AOM rate profiles around the SMTZ. The best-fit straight lines through the sulfate and methane data were used to estimate their fluxes into the SMTZ $\left(J_{1 \mathrm{~b}, \mathrm{~s}} / J_{1 \mathrm{~b}, \mathrm{~m}}=\right.$ 0.99). Symbols indicate individual model data points. (C) Sulfate and DIC profiles above the SMTZ, as well as the normalized, cumulative rate of organic matter oxidation in the surface sediments (NCOMX). Note here that the sulfate and DIC profiles are highly linear in a region of the sediment between $\sim 30$ and $120 \mathrm{~cm}$ sediment depth, where OMX still occurs. $N C O M X$ is defined as

$$
\operatorname{NCOMX}(z)=100 \cdot\left(\int_{0}^{z} \frac{k_{\mathrm{OM}} F G S}{K_{m}+S} d z\right) /\left(\int_{0}^{\infty} \frac{k_{\mathrm{OM}} F G S}{K_{m}+S} d z\right)
$$

where both integrals were solved by trapezoidal approximations using the numerical model results.

Case 3: Low reactive POC flux, no methanogenesis, external methane flux from below: Here, carbon loading to the sediments is such that in the absence of an external methane flux from below, the model profiles would be similar to those discussed above for case 1 sediments. However, the presence of an upward methane flux results in complete sulfate depletion in the sediments and the development of a deep reaction zone (i.e., the SMTZ) where AOM predominates. The depth at which this occurs ( $z_{\text {smtz }}$, see below) is controlled primarily by the magnitude of the upward methane flux $\left(J_{\mathrm{lb}, \mathrm{m}}\right)$ and secondarily by the consumption of sulfate during OMX in the surface sediments. The latter determines the depth in the sediments at which sulfate profiles begin to appear linear $\left(z_{\mathrm{omx}}\right)$ and the extent of sulfate depletion in the surface sediments due to OMX $\left(\Delta S_{\text {omx }}\right)$, which occurs roughly within the depth zone 0 to $z_{\text {omx }}$. To illustrate this observation, if we assume here that OMX does not occur to any appreciable extent at the SMTZ (see discussions below for verification), then

$$
J_{\mathrm{lb}, \mathrm{m}}=-\varphi D_{\mathrm{S}} \frac{\partial S}{\partial z} \approx-\varphi D_{\mathrm{S}} \frac{S_{\mathrm{o}}-\Delta S_{\mathrm{omx}}}{z_{\mathrm{smtz}}-z_{\mathrm{omx}}}
$$

and,

$$
z_{\mathrm{smtz}} \approx z_{\mathrm{omx}}+\frac{-\varphi D_{\mathrm{S}}}{J_{\mathrm{lb}, \mathrm{m}}}\left(S_{\mathrm{o}}-\Delta S_{\mathrm{omx}}\right)
$$

Furthermore, if $z_{\text {omx }}$ and $\Delta S_{\text {omx }}$ are small compared with $z_{\mathrm{smtz}}$ and $S_{\mathrm{o}}$ (the bottom water sulfate concentration), then

$$
z_{\mathrm{smtz}} \approx-\varphi D_{\mathrm{S}} S_{\mathrm{o}} / J_{\mathrm{lb}, \mathrm{m}}
$$

Equation $21 \mathrm{~b}$ can also be used to estimate the magnitude of the upward methane flux by determining $z_{\mathrm{smtz}}$ using porewater sulfate profiles (Borowski et al. 1996).

For the case 3 base model run (Fig. 7), we see slight curvature in the sulfate profile near the sediment surface (associated with OMX), below which the sulfate profile is highly linear down to the SMTZ, where AOM occurs. Near the SMTZ, the ratio of the downward diffusive sulfate flux to the upward methane flux is $\sim 1$, consistent with the lack of OMX consuming sulfate in the SMTZ. Decreasing the upward methane flux by a factor of two leads to an increase in $z_{\text {smtz }}$ by roughly a 
Table 3. Depth of SMTZ $\left(z_{\text {smtz }}\right)$ for case 3 model runs.*

\begin{tabular}{lcccc}
\hline \hline & $\begin{array}{c}J_{\mathrm{lb}, \mathrm{m}} \\
\left(\mathrm{mol} \mathrm{m}^{-2} \mathrm{yr}^{-1}\right)\end{array}$ & $\begin{array}{c}J_{\mathrm{POC}} \\
\left(\mathrm{mol} \mathrm{m}^{-2} \mathrm{yr}^{-1}\right)\end{array}$ & $\begin{array}{c}z_{\text {smtz }} \\
(\text { model; cm }) \dagger\end{array}$ & $\begin{array}{c}z_{\text {smtz }} \\
(\text { Eq. 21b; cm })\end{array}$ \\
\hline Base run $\dagger$ & -0.2 & 0.3 & 136 & 140 \\
$0.5 J_{\mathrm{lb}, \mathrm{m}}$ & -0.1 & 0.3 & 264 & 279 \\
Base run & -0.2 & 0.3 & 136 & 140 \\
$0.75 J_{\text {POC }}$ & -0.2 & 0.22 & 142 & 140 \\
$0.5 J_{\text {POC }}$ & -0.2 & 0.15 & 147 & 140 \\
\hline
\end{tabular}

* With the exception of the listed changes to $J_{\mathrm{lb}, \mathrm{m}}$ and $J_{\mathrm{POC}}$, these model runs used the case 3 model parameters listed in Table 1.

$\dagger$ On the basis of model data, and defined here as the sediment depth at which $S$ becomes $<0.1 \mathrm{mmol} \mathrm{L}^{-1}$.

t See Figs. 7 and 8.

factor of two (Table 3), consistent with Eq. 21 b. Decreasing the flux of reactive POC to the sediments (which will decrease OMX near the sediment surface and therefore affect $\Delta S_{\text {omx }}$ and $z_{\text {omx }}$ ) has a very small effect on $z_{\text {smtz }}$, again consistent with this discussion. In all of these additional case 3 model runs, the ratio of the downward diffusive sulfate flux to the upward methane flux was also $\sim 1$.

What is also particularly interesting here is that in Fig. 7, we see that the sulfate and DIC profiles are highly linear from $\sim 30 \mathrm{~cm}$ below the sediment surface down to the SMTZ at $\sim 130 \mathrm{~cm}$, despite low rates of OMX still occurring below this depth. Specifically, only $\sim 70 \%$ of the total depth-integrated OMX occurs in the upper $30 \mathrm{~cm}$ of sediment, with the remaining $\sim 30 \%$ occurring below this depth, where linear pore-water gradients would seem to imply a diffusion-only situation. Thus, we have a situation in which low rates of OMX occur over a large portion of the sediments above the SMTZ (here, $\sim 30-120 \mathrm{~cm}$ ) coupled with high rates of AOM focused on the smaller region of the SMTZ (here, at $\sim 120-140 \mathrm{~cm}$ ), and we see that this interplay appears to partially mask the curvature in pore-water profiles in the middepth region of the sediments. While linearity in pore-water profiles ultimately results from a region in the sediments in which diffusion alone occurs, the location of the linear region does not identically match the region in the sediments in which no in situ reactions occur.

In all case 3 model runs, DIC : sulfate property-property plots are not a straight line over the complete range of $\Delta$ sulfate values (e.g., see Fig. 8), and the end-member slopes of these curves provide evidence for the occurrence of OMX and AOM in the sediments. The slope of the line at large negative $\Delta$ sulfate (or large positive $\Delta \mathrm{DIC}$ ) values results in an $r_{\mathrm{C}: \mathrm{S}}$ value consistent with the occurrence of AOM (which is the dominant process in the region of sediments where such concentration changes are observed). In contrast, the value of $r_{\mathrm{C}: \mathrm{S}}$ based on the slope of the line at low values of negative $\Delta$ sulfate appears to record information about both OMX and AOM through the entire sediment column (Table 4), despite these concentration data coming solely from the surface sediments, where only OMX occurs. This can be seen in Table 4 by comparing the low negative $\Delta$ sulfate values of $r_{\mathrm{C}: \mathrm{S}}$ with the ratio of the depth-integrated
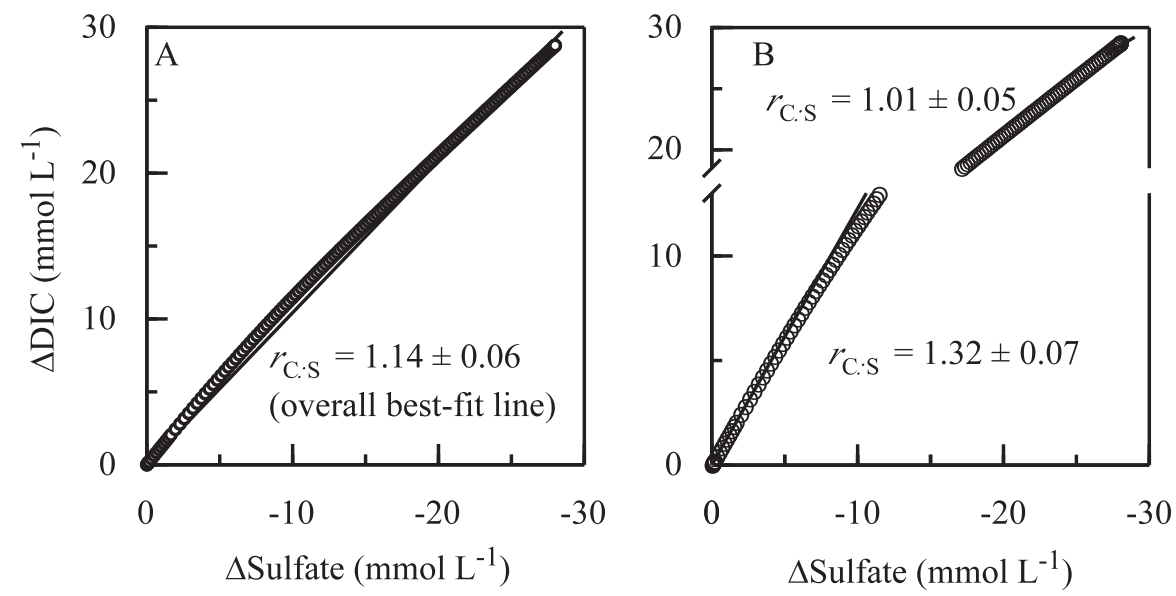

Fig. 8. (A) The DIC: sulfate property-property plot for the model results shown in Fig. 7 (case 3 base run). The value of $r_{\mathrm{C}: \mathrm{S}}$ shown here was determined using a fit to all model data (open circles) from the zone of sulfate reduction, despite the obvious curvature in the data, (see the text for details). (B) The same DIC: sulfate property-property plot showing end-member linear fits to the data (and the accompanying $r_{\mathrm{C}: \mathrm{s}}$ values) for low and high negative $\Delta$ sulfate values (note the scale break on the $y$-axis). Similar trends were seen in the DIC: sulfate property-property plots for the results from the other case 3 model runs discussed in Tables 3 and 4. 
Table 4. Estimates of $r_{\mathrm{C}: \mathrm{S}}$ for case 3 model runs.

\begin{tabular}{|c|c|c|c|c|}
\hline Model results & Base run & $0.5 J_{\mathrm{lb}, \mathrm{m}}$ & $0.75 J_{\mathrm{POC}}$ & $0.5 J_{\mathrm{POC}}$ \\
\hline $\begin{array}{l}\text { Depth-integrated rate of } \\
\text { DIC production }\end{array}$ & 0.48 & 0.39 & 0.40 & 0.33 \\
\hline \multicolumn{5}{|c|}{$\begin{array}{l}\text { Depth-integrated rate of } \\
\text { sulfate reduction }\end{array}$} \\
\hline$(D I R S) \dagger$ & 0.36 & 0.27 & 0.32 & 0.28 \\
\hline$D I R C: D I R S$ & 1.33 & 1.45 & 1.29 & 1.22 \\
\hline$r_{\mathrm{C}: \mathrm{S}}($ low $\Delta$ sulfate $) \ddagger$ & 1.32 & 1.43 & 1.27 & 1.20 \\
\hline$r_{\mathrm{C}: \mathrm{S}}^{\mathrm{app} \mathrm{S}} \S$ & 1.39 & 1.50 & 1.34 & 1.28 \\
\hline
\end{tabular}

* With the exception of the values of $J_{\mathrm{lb}, \mathrm{m}}$ and $J_{\mathrm{POC}}$ listed in Table 3, the case 3 model parameters listed in Table 1 were used in these model runs.

$\dagger$ The depth-integrated rate of DIC production $\left(\right.$ DIRC, $\left.\mathrm{mol} \mathrm{m}^{-2} \mathrm{yr}^{-1}\right)$ was calculated as

$$
D I R C=\varphi \int\left(\frac{k_{\mathrm{OM}} F G S}{K_{m}+S}+f_{\mathrm{S}} k_{\mathrm{OM}} L_{3} F G+k_{\mathrm{aom}} S M\right) d z
$$

(see Eq. 12 and the text for details). The first two terms in this integral account for DIC production by OMX, which is driven by the deposition and burial of reactive POC, and the third term accounts for DIC production by AOM, which is driven by the upward flux of methane that is completely oxidized to DIC. On the basis of Eq. 9, the depth-integrated rate of sulfate reduction $\left(D I S R, \mathrm{~mol} \mathrm{~m}^{-2} \mathrm{yr}^{-1}\right)$ was calculated as:

$$
D I S R=\varphi \int\left(k_{\mathrm{OM}} \frac{L_{1} F G S}{K_{m}+S}+k_{\mathrm{aom}} S M\right) d z
$$

Both integrals were solved by trapezoidal approximations using numerical model solutions and parameters in Tables 1 and 3 .

\$ On the basis of a DIC: sulfate property-property plot, as discussed in the text (e.g., see Fig. 8B).

$\S$ Determined using Eq. 27, as discussed in the text.

rates of DIC production to sulfate reduction $(D I R C: D I R S)$ over the entire sediment column.

These observations are discussed below and also verified using an analytical solution to a simplified version of our AOM-OMX numerical model.

Application of an analytical model to the examination of DIC : sulfate property-property plots-Here, we start with Eqs. 9, 10, and 12 for reactive POC, sulfate, and DIC and simplify the equations by neglecting pore-water advection and setting $K_{\mathrm{m}}$ equal to 0 . As discussed above, OMX coupled to sulfate reduction in the surface sediments then becomes first order with respect to the reactive POC concentration and is independent of sulfate concentration (see Eq. 19). Reactions occurring at depth in the sediments, specifically AOM driven by an upward methane flux, are not explicitly modeled here but are accounted for by specifying DIC and sulfate fluxes into or out of the deeper sediments across the lower model boundary (e.g., based on the results in Fig. 2, this lower model boundary would be at 45-50 cm sediment depth).

With these assumptions, the analytical solution to the modified forms of Eqs. 10 and 12 for dissolved sulfate $(S)$ and DIC $(C)$ can be written as

$$
I=I_{\mathrm{O}}+B_{1, i} z+B_{2, i}\left(1-e^{-\alpha z}\right)
$$

where $I$ is either $C$ or $S, I_{\mathrm{o}}$ is the bottom water concentration of that solute, $\alpha=k_{\mathrm{OM}} / \omega, k_{\mathrm{OM}}$ is the firstorder rate constant for reactive POC degradation, and $\omega$ is the sediment accumulation rate. The two fitting parameters in Eq. 22 are given by

$$
\begin{aligned}
& B_{1, i}=-H_{i} / \varphi D_{i} \\
& B_{2, \mathrm{i}}=\frac{r_{\mathrm{i}} F k_{\mathrm{OM}} G_{\mathrm{O}}}{\alpha^{2} D_{\mathrm{i}}}
\end{aligned}
$$

where: $\varphi, D_{i}$, and $F$ are defined in Table 1 or the section "Development and implementation of a numerical AOMOMX model"; $G_{\mathrm{O}}$ is the concentration of reactive POC at the sediment surface; $H_{i}$ is the flux of solute $i$ at the lower model boundary; and $r_{i}=1$ for $C$ and $=-1 / r_{\mathrm{C}: \mathrm{S}}$ for $S$.

Using these equations to examine the results in Fig. 8, we start by taking the differentials of Eq. 22 for $S$ and $C$, allowing us to write the slope of such a property-property plot as

$$
\frac{d C}{d S}=\frac{D_{\mathrm{S}}}{D_{\mathrm{C}}}\left[\frac{-\left(H_{\mathrm{C}} / \varphi\right)+\omega F G_{\mathrm{o}} e^{-\alpha z}}{-\left(H_{\mathrm{S}} / \varphi\right)-\left(1 / r_{\mathrm{C}: \mathrm{S}}\right) \omega F G_{\mathrm{o}} e^{-\alpha z}}\right]
$$

and, by comparison with Eq. 1, we can think of the term in the large square brackets as the "apparent" $r_{\mathrm{C}: \mathrm{S}}\left(r_{\mathrm{C}: \mathrm{S}}^{\mathrm{app}}\right)$,

$$
r_{\mathrm{C}: \mathrm{S}}^{\mathrm{app}}=\frac{-\left(H_{\mathrm{C}} / \varphi\right)+\omega F G_{\mathrm{o}} e^{-\alpha z}}{\left(H_{\mathrm{S}} / \varphi\right)+\left(1 / r_{\mathrm{C}: \mathrm{S}}\right) \omega F G_{\mathrm{o}} e^{-\alpha z}}
$$

Furthermore, in either the numerator or the denominator of $r_{\mathrm{C}: \mathrm{S}}^{\mathrm{app}}$, the first term represents the contribution from AOM in the deeper part of the sediments below the analytical model lower boundary, and the second term is the contribution from OMX in the surface sediments. 

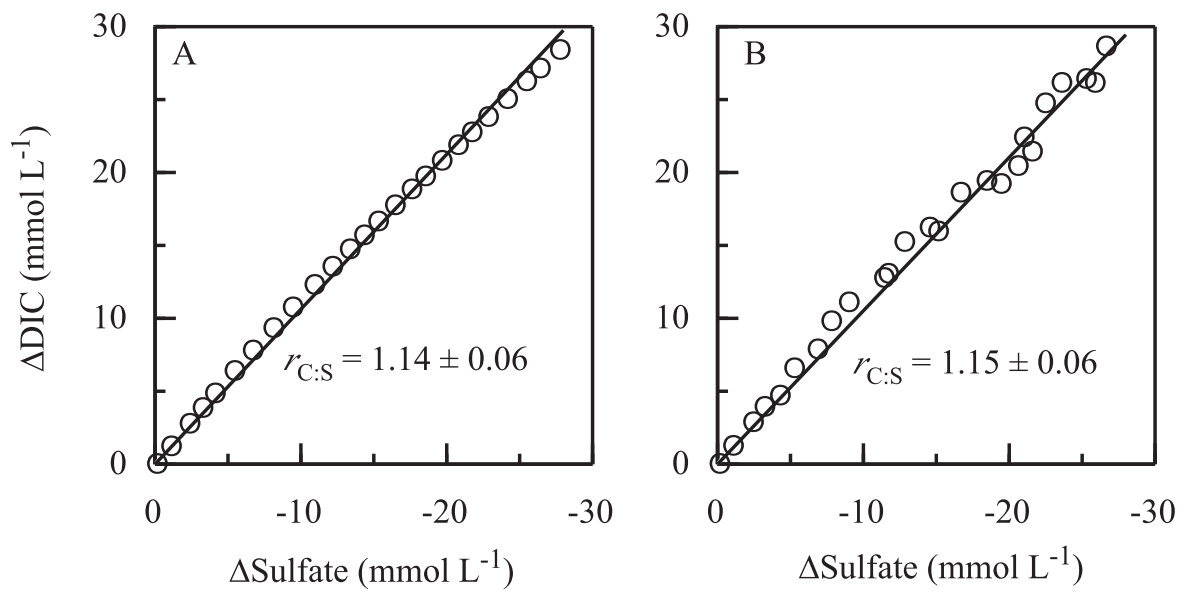

Fig. 9. (A) A DIC:sulfate property-property plot for the model results shown in Figs. 7 and 8 , in which the model output has been down-sampled from the original $\sim 200$ data points shown in these figures to the 25 data points shown here that are roughly distributed evenly over the depth zone of sulfate reduction. Despite this down-sampling, there is still evidence here of the curvature seen in Fig. 8A, and the value of $r_{\mathrm{C}: \mathrm{S}}$ based on the best-fit straight line through these data is identical to that in Fig. 8A. (B) The down-sampled data in Fig. 9A with random errors (up to $\pm 5 \%$ ) added to each data point. The curvature seen in part $\mathrm{A}$ is now absent, and the data are more randomly distributed around the best-fit line. However, the best-fit line through these data results in virtually the same $r_{\mathrm{C}: \mathrm{S}}$ value as in Figs. 8A and 9A.

We can now examine the end-member values of $r_{\mathrm{C}: \mathrm{S}}^{\mathrm{app}}$ and compare them with similar values based on the case 3 numerical model results reported in Tables 3 and 4 and Fig. 8. To do this, we first fit the sulfate and DIC concentration data from the four case 3 numerical model runs with the analytical model (Eqs. 22 and 23) by adjusting the values of $G_{\mathrm{o}}, k_{\mathrm{OM}}, H_{\mathrm{C}}$, and $H_{\mathrm{S}}$. The best fit of the numerical model data with these analytical equations was excellent (normalized root mean square errors $<0.5 \%$ in all cases).

At depth in the sediments, sulfate concentrations are low, DIC concentrations are high, and $\Delta S$ or $\Delta C$ values are large negative or positive numbers, respectively. Because $z$ is large, the exponential terms in the numerator and denominator of $r_{\mathrm{C}: \mathrm{S}}^{\mathrm{app}}$ in Eq. 24 will approach zero and

$$
r_{\mathrm{C}: \mathrm{S}}^{\mathrm{app}, D} \approx-H_{\mathrm{C}} / H_{\mathrm{S}}
$$

Because we have assumed here that AOM is the only process consuming sulfate and producing DIC at depth, these two fluxes should be roughly equal in magnitude (but of opposite signs), and $r_{\mathrm{C}: \mathrm{S}}^{\mathrm{app}, D}$ should approach 1 . The actual values of $r_{\mathrm{C}: \mathrm{S}}^{\mathrm{app}, D}$ based on these fits of the analytical model to the case 3 numerical model results (i.e., using Eq. 26) ranged from 1.05 to 1.13 , in very good agreement with similar estimates obtained directly with the numerical model results (e.g., see Fig. 8B).

Similarly, near the sediment surface, sulfate concentrations are high, DIC concentrations are low, and negative $\Delta S$ or positive $\Delta C$ values are low. Since here $z$ is small, $r$ C.S can be approximated as

$$
r_{\mathrm{C}: \mathrm{S}}^{\mathrm{app} S}=\frac{-\left(H_{\mathrm{C}} / \varphi\right)+\omega F G_{\mathrm{o}}}{\left(H_{\mathrm{S}} / \varphi\right)+\left(1 / r_{\mathrm{C}: \mathrm{S}}\right) \omega F G_{\mathrm{o}}}
$$

and now we see that the numerator and denominator incorporate contributions from both $\mathrm{AOM}$ at depth and OMX near the sediment surface. Again, fits of the analytical model to the case 3 numerical model results yield values of $r_{\mathrm{C}: \mathrm{S}}^{\mathrm{app}, S}$ (determined with Eq. 27) that were in excellent agreement with the analogous values in Table 4 determined directly with numerical model results, as in, for example, Fig. 8B.

Using this same approach, we can also re-examine the case 2 model results (Figs. 5, 6), and the resulting fitting parameters can then be used to determine $r_{\mathrm{C}: \mathrm{S}}^{\mathrm{app}}$ with either Eqs. 25, 26, or 27. All three equations yield a value of 1.7 for $r_{\mathrm{C}: \mathrm{S}}^{\mathrm{app}}$. This observation provides further evidence for the conclusion reached in the section discussing the case 2 results that internal cycling of methane by in situ methanogenesis and AOM does not lead to deviations in the value of $r_{\mathrm{C}: \mathrm{S}}$ from that seen solely for the occurrence of OMX

A comparison of Eqs. 26 and 27 also provides a conceptual explanation for the values of the end-member slopes in the property-property plots of case 3 model results (e.g., Fig. 8B). Specifically, it illustrates that processes in both the surface and deep sediments affect the properties of the surface sediments, whereas deep sediments are affected only by processes taking place in the deep sediments. Because deeper sediments (where AOM largely occurs) are also older than surface sediments (where OMX predominates), this equation suggests that we might be able to think about this observation in terms of processes in older (deeper) sediments affecting the properties of younger (shallower) sediments, but not vice versa.

Implications of these model results to the interpretation of field data-A final point to consider here is why the 


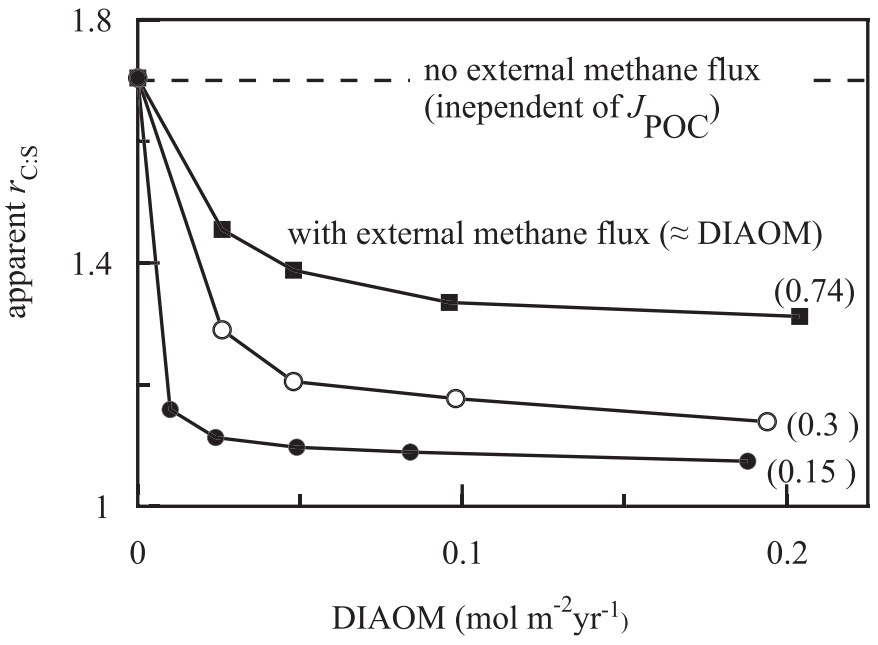

Fig. 10. The apparent $r_{\mathrm{C}: \mathrm{S}}$, determined from a linear fit to "complete" DIC and sulfate model data sets, as in Fig. 8A, vs. the depth-integrated rate of AOM $(D I A O M)$. Different curves represent results for different values of $J_{\mathrm{POC}}\left(\mathrm{mol} \mathrm{m} \mathrm{m}^{-2} \mathrm{yr}^{-1}\right.$, values in parentheses) based on reactive POC fluxes used in previous model runs. In the presence of an external methane flux (curves with solid lines and symbols) DIAOM is approximately equal to $J_{1 \mathrm{~b}, \mathrm{~m}}$. These fluxes and the remaining parameters used in the model runs shown here are listed in Table 1 . The horizontal dashed line indicates that in the absence of an external methane flux, the apparent value of $r_{\mathrm{C}: \mathrm{S}}$ is independent of $J_{\mathrm{POC}}$ and DIAOM because of the tight coupling of AOM and in situ methanogenesis (see the subsection "Case 2: In situ methanogenesis, no external methane flux" for details). DIAOM was calculated here as

$$
D I A O M=\varphi \int k_{\mathrm{aom}} S M d z
$$

and the integral was solved by trapezoidal approximations using numerical model results.

curvature seen in property-property plots with case 3 model data (Fig. 8) is not discernible in field data such as those in Fig. 1, despite predicted values of $r_{\mathrm{C}: \mathrm{S}}$ based on plots such as Fig. 1 consistent with there being an external methane source to these sediments. As a possible explanation, we first note that model simulations such as that in Fig. 8 have $>200$ model data points with essentially no error associated with each data point, allowing for the expression of the somewhat subtle (but nonetheless observable) curvature in the data. To examine this point further, we have taken the model data shown in Fig. 8 and sampled it to match the data density of a typical pore-water profile. This is shown in Fig. 9A. Even at the lower data density shown here, some slight curvature is still evident in the data, and the best-fit line through the sampled data yields an apparent $r_{\mathrm{C}: \mathrm{S}}$ value identical to that seen when fitting the complete data set in Fig. 8A to a straight line. In contrast, when we add random errors (up to $\pm 5 \%$ ) to the sampled data (Fig. 9B), the curvature in the data is lost, although the apparent $r_{\mathrm{C}: \mathrm{S}}$ value based on the best-fit line in Fig. 9B remains virtually unchanged from the previous two estimates in Figs. 8A and 9A.
That these three estimates of the apparent $r_{\mathrm{C}: \mathrm{S}}$ for this model data set are essentially identical is even more interesting in the context of Fig. 10. Here, we see that for a given flux of reactive POC to the sediments, the apparent $r_{\mathrm{C}: \mathrm{S}}$ value based on a linear regression fit to the complete model data set shows an inverse relationship with the depth-integrated rate of AOM, which is essentially equal to the upward external methane flux when this flux is present. On the basis of the previous discussion, this apparent $r_{\mathrm{C}: \mathrm{S}}$ value should also be similar to that we can obtain with real sediment data for a site with these same model characteristics (i.e., compare Figs. 8A and 9B). This then suggests that we may be able to use real sediment POC and porewater data (the latter through DIC:sulfate propertyproperty plots) to obtain information about the relative importance of OMX and AOM driven by an external methane flux. Thus, although the ability to see curvature in DIC: sulfate property-property plots with field data might be difficult, observed deviations in $r_{\mathrm{C}: \mathrm{S}}$ values from predicted end-member values (i.e., 1 for AOM or 1.7-2 for OMX) could still provide useful information about the occurrence and relative importance of OMX and AOM in sediments driven by an upward external methane flux.

However, unless carbonate precipitation is also accounted for, such deviations in values of $r_{\mathrm{C}: \mathrm{S}}$ from predicted endmember values do not provide unequivocal information about the occurrence of OMX and AOM in sediments. We hope to address this problem using future versions of this model, in part by including equations for pore-water $\left[\mathrm{Ca}^{2+}\right]$ (and perhaps $\left[\mathrm{Mg}^{2+}\right]$ ) in the model and by also explicitly incorporating carbonate speciation (Boudreau 1987; Zeebe 2007) into model equations.

\section{Acknowledgments}

We thank Sabrina Crispo, Malee Jinuntuya, Leah Johnson, Raman Paul, Amy Pitts, Jonathon Polly, Nuria Protopopescu, and the Captain and crew of RV Point Sur for their assistance in our work in Santa Monica Basin. We also thank two anonymous reviewers who provided useful comments on the first version of this manuscript.

This work was funded by grants from the National Science Foundation (OCE- 0727179 to D.J.B. and OCE-0726819 to T.K.).

\section{References}

Alperin, M. J., And T. M. Hoehler. 2009. Anaerobic methane oxidation by archaea/sulfate-reducing bacteria aggregates: 1 . Thermodynamic and physical constraints. Am. J. Sci. 309: 869-957, doi:10.2475/10.2009.01

, W. S. Reeburgh, and A. H. Devol. 1992. Organic carbon remineralization and preservation in sediments of Skan Bay, Alaska, p. 99-122. In J. K. Whelan and J. W. Farrington [eds.], Productivity, accumulation, and preservation of organic matter in recent and ancient sediments. Columbia Univ. Press.

Berelson, W. M., D. E. Hammond, and K. S. Johnson. 1987. Benthic fluxes and cycling of biogenic silica and carbon in two southern California borderland basins. Geochim. Cosmochim. Acta 51: 1345-1363, doi:10.1016/0016-7037(87)90320-6 , M. Prokopenko, F. J. Sansone, A. W. Graham, J. McManus, And J. M. Bernhard. 2005. Anaerobic diagenesis of silica and carbon in continental margin sediments: Discrete 
zones of $\mathrm{TCO}_{2}$ production. Geochim. Cosmochim. Acta 69: 4611-4629, doi:10.1016/j.gca.2005.05.011

Berner, R. A. 1977. Stoichiometric models for nutrient regeneration in anoxic sediments. Limnol. Oceanogr. 22: 781-786, doi:10.4319/1o.1977.22.5.0781

Borowski, W., C. Paull, And W. Ussler, III. 1996. Marine porewater sulfate profiles indicate in situ methane flux from underlying gas hydrate. Geology 24: 655-658, doi:10.1130/ 0091-7613(1996)024<0655:MPWSPI > 2.3.CO;2

Borowski, W. S., C. K. Paull, and W. Ussler, III. 1999. Global and local variations of interstitial sulfate gradients in deepwater, continental margin sediments: Sensitivity to underlying methane and gas hydrates. Mar. Geol. 159: 131-154, doi:10.1016/S0025-3227(99)00004-3

Boudreau, B. P. 1987. A steady-state diagenetic model for dissolved carbonate species and $\mathrm{pH}$ in the porewaters of oxic and suboxic sediments. Geochim. Cosmochim. Acta 51: 1985-1996, doi:10.1016/0016-7037(87)90187-6

1997. Diagenetic models and their implementation. Springer-Verlag.

Burdige, D. J. 2006. Geochemistry of marine sediments. Princeton Univ. Press.

- And J. Homstead. 1994. Fluxes of dissolved organic carbon from Chesapeake Bay sediments. Geochim. Cosmochim. Acta 58: 3407-3424, doi:10.1016/0016-7037(94)90095-7

, R. C. Zimmerman, And X. Hu. 2008. Rates of carbonate dissolution in permeable sediments estimated from pore water profiles: the role of seagrasses. Limnol. Oceanogr. 53: 549-565, doi:10.4319/1o.2008.53.2.0549

Christensen, C. J., D. S. Gorsline, D. E. Hammond, and S. P. LuND. 1994. Non-annual laminations and expansion of anoxic basin-floor conditions in Santa Monica Basin, California Borderland, over the past four centuries. Mar. Geol. 116: 399-418, doi:10.1016/0025-3227(94)90054-X

Dale, A., P. Regnier, N. Knab, B. Jorgensen, and P. Van CAPPELlen. 2008. Anaerobic oxidation of methane (AOM) in marine sediments from the Skagerrak (Denmark): II. Reaction-transport modeling. Geochim. Cosmochim. Acta 72: 2880-2894, doi:10.1016/j.gca.2007.11.039

Dhakar, S. P., And D. J. Burdige. 1996. A coupled, non-linear, steady state model for early diagenetic processes in pelagic sediments. Am. J. Sci. 296: 296-330, doi:10.2475/ajs.296.3.296

Dickens, G. R. 2001. Sulfate profiles and barium fronts in sediment on the Blake Ridge: Present and past methane fluxes through a large gas hydrate resevoir. Geochim. Cosmochim. Acta 65: 529-543, doi:10.1016/S0016-7037(00)00556-1

Emerson, S., V. Grundmanis, and D. Graham. 1982. Carbonate chemistry in marine pore waters: MANOP sites C and S. Earth Planet. Sci. Lett. 61: 220-232, doi:10.1016/0012821X(82)90055-3

Fossing, H., T. G. Ferdelman, and P. Berg. 2000. Sulfate reduction and methane oxidation in continental margin sediments influenced by irrigation (south-east Atlantic off Namibia). Geochim. Cosmochim. Acta 64: 897-910, doi:10.1016/S0016-7037(99)00349-X

Goldhaber, M. B., R. C. Aller, J. K. Cockran, J. K. Rosenfeld, C. S. Martens, and R. A. Berner. 1977. Sulfate reduction, diffusion, and bioturbation in Long Island Sound sediments: Report of the FOAM Group. Am. J. Sci. 277: 193-237, doi:10.2475/ajs.277.3.193

Gorsline, D. 1992. The geological setting of Santa Monica and San Pedro Basins, California Continental Borderland. Prog. Oceanogr. 30: 1-36, doi:10.1016/0079-6611(92)90008-N

Hall, P. O. J., AND R. C. Aller. 1992. Rapid, small-volume flowinjection methods for $\sum \mathrm{CO}_{2}$ and $\mathrm{NH}_{4}^{+}$in marine and fresh waters. Limnol. Oceanogr. 37: 1113-1119, doi:10.4319/ lo.1992.37.5.1113

Hammond, D. E., P. Giodani, W. M. Berelson, and R. Poletti. 1999. Diagenesis of carbon and nutrients and benthic exchange in sediments of the northern Adriatic Sea. Mar. Chem. 66: 53-97, doi:10.1016/S0304-4203(99)00024-9

Harrison, B., H. Zhang, W. Berelson, and V. Orphan. 2009. Variations in archaeal and bacterial diversity associated with the sulfate-methane transition zone in continental margin sediments (Santa Barbara Basin, California). Appl. Environ. Microbiol. 75: 1487-1499, doi:10.1128/AEM.01812-08

Hein, J., W. Normark, B. McIntyre, T. Lorenson, and C. Powell. 2006. Methanogenic calcite, ${ }^{13} \mathrm{C}$-depleted bivalve shells, and gas hydrate from a mud volcano offshore southern California. Geology 34: 109-112, doi:10.1130/G22098.1

Higgins, J., And D. Schrag. 2010. Constraining magnesium cycling in marine sediments using magnesium isotopes. Geochim. Cosmochim. Acta 74: 5039-5053, doi:10.1016/ j.gca.2010.05.019

Huh, C.-A., D. L. Zahnle, L. F. Small, and V. E. Noshin. 1987. Budgets and behaviors of uranium and thorium series isotopes in Santa Monica Basin sediments. Geochim. Cosmochim. Acta 51: 1743-1754, doi:10.1016/00167037(87)90352-8

JAHNKE, R. A. 1990. Early diagenesis and recycling of biogenic debris at the seafloor, Santa Monica Basin, California. J. Mar. Res. 48: 413-436, doi:10.1357/002224090784988773

Jørgensen, B. B., AND R. J. PARKes. 2010. Role of sulfate reduction and methane production by organic carbon degradation in eutrophic fjord sediments (Limfjorden, Denmark). Limnol. Oceanogr. 55: 1338-1352, doi:10.4319/ 10.2010.55.3.1338

Knab, N. J., A. W. Dale, K. Lettmann, H. Fossing, and B. B. JørGensen. 2008. Thermodynamic and kinetic control on anaerobic oxidation of methane in marine sediments. Geochim. Cosmochim. Acta 72: 3746-3757, doi:10.1016/ j.gca.2008.05.039

Leslie, B. W., D. E. Hammond, W. M. Berelson, and S. P. Lund, 1990. Diagenesis in anoxic sediments from the California continental borderland and its influence on iron, sulfur, and magnetite behavior. J. Geophys. Res. 95: 4453-4470, doi:10.1029/JB095iB04p04453

Lustwerk, R. L., AND D. J. Burdige. 1995. Elimination of dissolved sulfide interference in the flow injection determination of $\sum \mathrm{CO}_{2}$ by the addition of molybdate. Limnol. Oceanogr. 40: 1011-1012, doi:10.4319/lo.1995.40.5.1011

Martens, C. S., D. B. Albert, and M. J. Alperin. 1998. Biogeochemical processes controlling methane in gassy coastal sediments - part 1. A model coupling organic matter flux to gas production, oxidation and transport. Cont. Shelf Res. 18: 1741-1770, doi:10.1016/S0278-4343(98)00056-9

, R. I. HAdDAd, AND J. P. Chanton. 1992. Organic matter accumulation, remineralization and burial in an anoxic marine sediment, p. 82-98. In J. K. Whelan and J. W. Farrington [eds.], Productivity, accumulation, and preservation of organic matter in recent and ancient sediments. Columbia Univ. Press.

Milkov, A. V., And R. SAsSEn. 2002. Economic geology of offshore gas hydrate accumulations and provinces. Mar. Petroleum Geol. 19: 1-11, doi:10.1016/S0264-8172(01)00047-2

Niewöhner, C., C. Hensen, S. Kasten, M. Zabel, and H. D. SCHulz. 1998. Deep sulfate reduction completely mediated by anaerobic methane oxidation in sediments of the upwelling area off Namibia. Geochim. Cosmochim. Acta 62: 455-464, doi:10.1016/S0016-7037(98)00055-6 
Normark, W., D. Piper, And R. Sliter. 2006. Sea level and tectonic control of middle to late Pleistocene turbidite systems in Santa Monica Basin, offshore California. Sedimentology 53: 867-897, doi:10.1111/j.1365-3091.2006.00797.x

Paull, C. K., W. R. Normark, W. Ussler, III, D. W. Caress, and R. Keaten. 2008. Association among active seafloor deformation, mound formation, and gas hydrate growth and accumulation within the seafloor of the Santa Monica Basin, offshore California. Mar. Geol. 250: 258-275, doi:10.1016/ j.margeo.2008.01.011

Reeburgh, W. S. 2007. Oceanic methane biogeochemistry. Chem. Rev. 107: 486-513, doi:10.1021/cr050362v

SCHIESSER, W. E. 1991. The numerical method of lines: Integration of partial differential equations. Academic Press.

Schulz, H. D., And M. Zabel [Eds.]. 2006. Marine geochemistry, 2nd ed. Springer-Verlag.

Sholkovitz, E. 1973. Interstitial water chemistry of the Santa Barbara Basin. Geochim. Cosmochim. Acta 37: 2043-2073, doi:10.1016/0016-7037(73)90008-2

Tipper, E. T., A. Galy, J. Gaillardet, M. J. Bickle, H. Elderfield, AND E. A. CARder. 2006. The magnesium isotope budget of the modern ocean: Constraints from riverine magnesium isotope ratios. Earth Planet. Sci. Lett. 250: 241-253, doi:10.1016/j.eps1.2006.07.037

Westrich, J. T., AND R. A. BERner. 1984. The role of sedimentary organic matter in bacterial sulfate reduction: The $G$ model tested. Limnol. Oceanogr. 29: 236-249, doi:10.4319/ 10.1984.29.2.0236

Zeebe, R. E. 2007. Modeling $\mathrm{CO}_{2}$ chemistry, d ${ }^{13} \mathrm{C}$, and oxidation of organic carbon and methane in sediment porewater: Implications for paleo-proxies in benthic foraminifera. Geochim. Cosmochim. Acta 71: 3238-3256, doi:10.1016/ j.gca.2007.05.004

Zhang, C. L., And B. Lanoll. 2004. Geomicrobiology and biogeochemistry of gas hydrates and cold seeps. Chem. Geol. 205: 187-194, doi:10.1016/j.chemgeo.2004.01.001

Associate editor: Bo Thamdrup

Received: 31 December 2010 Accepted: 01 June 2011 Amended: 07 June 2011 